\title{
The impact of snow loss and soil moisture on convective precipitation over the Rocky Mountains under climate warming
}

\author{
Brendan Wallace $^{1}$ (D) Justin R. Minder ${ }^{1}$
}

Received: 21 February 2020 / Accepted: 29 December 2020 / Published online: 28 January 2021

(c) The Author(s) 2021

\begin{abstract}
Warm season moist diurnal convection can be particularly sensitive to changes in land surface characteristics such as snow cover and soil moisture. Over regions of mountainous terrain, climate change is expected to reduce snow cover along the lowelevation seasonal snowpack margin. These snow reductions alter surface albedo and soil moisture content, leading to changes in surface fluxes and alterations in mesoscale orographic circulations that act to transport moisture and provide ascent. A set of convection-permitting regional climate simulations centered on the Rocky Mountains of Colorado are conducted from April through July across a period of 12 years (2002-2013). These include a reanalysis forced control run (CTR), a pseudo global warming run (PGW), and an additional altered land surface run (DSURF) used to isolate the effects of the snow albedo and soil moisture changes on orographic convection. Over the mountains, daytime hourly precipitation accumulation (0900-1800 MST) decreased in PGW by an average of $4.2 \%$ while precipitation in DSURF increased by $12.5 \%$. On days with weak synoptic forcing, the PGW response more closely follow the DSURF response with daytime hourly increases averaging $29.7 \%$ for PGW and $28.7 \%$ for DSURF. For PGW, hourly daytime precipitation intensity increases of up to $82 \%$ overcome reductions in precipitation frequency to produce higher accumulations. DSURF shows smaller increases in intensity of up to $23 \%$ and broad increases in daytime frequency indicating that surface changes act to moderate reductions in the frequency of convective precipitation. Reduced snow cover contributes to this convective response by increasing convective instability and boundary layer moisture and decreasing lifting condensation level over the high terrain. Alterations in orographic thermal circulations contribute to this response by converging moisture over the high terrain and enhancing mesoscale ascent.
\end{abstract}

Keywords Orographic convection $\cdot$ Convection permitting modeling $\cdot$ Land surface-atmosphere interactions $\cdot$ Regional climate

\section{Introduction}

In the event of prevailing flow traveling over a mountain barrier, orographic ascent may cause lifted air to become saturated, leading to condensation of clouds and precipitation in the form of rain or snow. In the absence of strong prevailing flow, thermally forced orographic circulations can also initiate convective clouds and precipitation through orographic ascent (e.g, Kirshbaum et al. 2018). Within the western United States, diurnal orographic convective precipitation

Brendan Wallace

bwallace3@albany.edu

1 Department of Atmospheric and Environmental Sciences, State University of New York, University at Albany, Earth Sciences Bldg., 1400 Washington Ave, Albany, NY 12222, USA is a recurring feature of warm season weather and largely contributes to local spatial maxima in thunderstorm occurrence (Wallace 1975; Carbone and Tuttle 2008). Typically, the warm season over the Intermountain West is characterized by weak large-scale forcing (Davis and Walker 1992). As such, diurnal convection is often forced locally over orography.

Local circulations driven by thermal contrasts between elevated terrain and the adjacent free atmosphere can help to initiate convection through leeside convergence zones during the day between upslope thermal flow and downwardly mixed prevailing synoptic flow (Banta 1984; Pielke 2001). These convergence zones also increase local instability through heat and moisture convergence (Barthlott et al. 2006; Mahrt 2006). Alternatively, observations taken during the CuPIDO field campaign in the Santa Catalina Mountains of Arizona by Demko and Geerts (2010) suggest 
that convective initiation can also occur independent of mesoscale convergence, triggered through elevated destabilization and an extension of the convective boundary layer. Kalthoff et al. (2011) similarly highlight the importance of elevated instability, noting a distinct reduction in convective inhibition (CIN) for mountain observation sites in Germany's Black Forest when compared to low-elevation sites as part of the Convective and Orographically-Induced Precipitation Study.

This dependence on local mechanisms for convective initiation makes convective precipitation influenced by topography highly sensitive to land surface characteristics, including snow cover and soil moisture. Snow cover can considerably impact local temperatures through its alteration of surface albedo and thermal properties (Cohen and Rind 1991). These modifications of the local temperature and energy budget can drive or modulate thermally forced circulations. Observations show that "snow breezes" can occur near the boundary between snow and bare ground on clear sky days with weak background flow (Taylor et al. 1998). Snow breezes over mountains can interact with topography to facilitate daytime drainage flow through suppression of the temperature gradient that drives thermal upslope flow (Segal et al. 1991). These drainage flows may increase convergence near the snow margin through interaction with upslope flow over snow free regions. High-resolution largeeddy simulations show that the contrast between snowcovered and snow-free ground can drive buoyancy induced flows that play an important role in the distribution of surface sensible heat fluxes (Mott et al. 2015).

Furthermore, soil moisture can also have a considerable impact on orographic convection (Imamovic et al. 2017). The spatial variability of soil moisture can be related to the spatial variability of snow cover due to the dependence of soil moisture on replenishment through snow melt (Williams et al. 2009). Soil moisture can have a considerable impact on rainfall through the soil-moisture precipitation feedbacks (e.g., Findell and Eltahir 1997). However, results vary with regards to the sign of the feedback. Over wet soils, enhanced convection can be caused by a combination of a reduction in the level of free convection and an increase in the concentration of moist static energy within the boundary layer (Schär et al. 1999; Eltahir 1998; Zhou and Geerts 2013). On the other hand, over dry soils, enhanced convection can be caused by an increase in the magnitude of dynamic forcing through invigorated thermal circulations and turbulent sensible heat fluxes that overcome increases in local stability (Wetzel et al. 1996; Taylor and Ellis 2006; Hauck et al. 2011; Barthlott and Kalthoff 2011). The sign of this feedback is dependent upon the long term soil moisture distribution (Rodriguez-Iturbe et al. 1991; Grayson et al. 1997) and can vary both seasonally and regionally (Ferguson and Wood 2011; Roundy et al. 2013; Song et al. 2016). Recent work has also demonstrated that the simulated soil moisture-precipitation feedback can be dependent on the heterogeneity of the soil moisture (Baur et al. 2018). In idealized convectionpermitting ensembles, dry soil heterogeneity can induce a negative soil moisture-precipitation feedback that weakens with increasing terrain height (Imamovic et al. 2017). Over the European Alps, Hohenegger et al. (2009) show that the sign of this response can depend upon model grid spacing and the use of a convective parameterization. Similar to Imamovic et al. (2017) they note that, at convection-permitting resolutions, drier soils lead to stronger turbulent heat fluxes that dynamically overcome stable layers aloft, leading to a negative soil moisture-precipitation feedback. Similar convection-parameterizing simulations at $12 \mathrm{~km}$ were also outperformed by convection-permitting simulations when determining the frequency and location of heavy precipitation events for the same region (Ban et al. 2014). Froidevaux et al. (2014) synthesize these results, using idealized cloud resolving simulations, and show how both a positive and negative soil moisture-precipitation feedback can exist dependent on the backgrounds winds. Similar to prior convection permitting simulations (e.g., Hohenegger et al. 2009; Ban et al. 2014), convective initiation is favored over dry soils. However, in an environment with stronger background winds, these storms may propagate over wetter soils where the intensification and maintenance of convection is favored.

Recently, regional climate models (RCM) at convectionpermitting scales have been used to examine changes in convective precipitation over the United States. In regions of high terrain, these simulations prove particularly useful because of their ability to capture complex snow and soil moisture patterns across the terrain and simulate finescale interactions between the atmosphere and topography (Di Luca et al. 2012; Prein et al. 2015; Kendon et al. 2017; Scaff et al. 2019). Prein et al. (2017) examined the change in distribution of convective precipitation events using output from a continental-scale convection-permitting RCM, finding that extreme summertime precipitation events show an increase for the entire domain due to increases in atmospheric moisture content while moderate precipitation events substantially decrease across large areas in the Great Plains and Midwestern United States but increase over the Intermountain West. Rasmussen et al. (2017) use the same simulations to examine changes in convective precipitation over the continental United States. They find a clear decrease in weak precipitation events (simulated reflectivity of 0-20 $\mathrm{dBZ}$ ) and an increase in extreme precipitation events (50-60 $\mathrm{dBZ}$ ). They connect these to changes in the convective environment, specifically, increases in both mixed layer convective available potential energy (MLCAPE) and mixed layer convective inhibition (MLCIN) for May and June. Looking at the regional response, there is a persistent increase in the frequency of precipitation events ranging from 20 to $50 \mathrm{dBZ}$ 
over the Intermountain West. These results agree with similar studies over the European Alps that also note a shift in the distribution of precipitation events towards less frequent, more intense systems (Ban et al. 2015; Giorgi et al. 2016).

Over the Rocky Mountains, anthropogenic climate change is expected to coincide with large reductions in snow cover (Rasmussen et al. 2011; Gao et al. 2011; Wi et al. 2012; Rasmussen et al. 2014; Liu et al. 2017; Truettner et al. 2019) and soil moisture (Wang 2005; Sheffield and Wood 2008; Zhao and Dai 2015; Mankin et al. 2017) which may influence the response of convective precipitation. Within this region, reductions in albedo associated with snow loss are the dominant driver of spatial variability in simulated winter and springtime warming through the snow-albedo feedback (SAF) (Letcher and Minder 2015; Rupp et al. 2017; Minder et al. 2018). Letcher and Minder (2017) analyzed high-resolution RCM simulations to examine the effects of SAFmodulated warming patterns on mountain slope circulations over the Rockies. They found that locally enhanced warming over mountains due to the SAF drove enhanced daytime upslope flow. These changes in slope winds also resulted in a convective response with an increase in clouds simulated along the snowpack margin. On a broader scale, Letcher and Minder (2018) perform a similar experiment looking at the relationship between projected snow cover reductions and the Front Range Mountain-Plain Circulation. They found that reduced snow cover resulted in a more vigorous daytime upslope branch of the solenoidal circulation. An enhanced convective response was also detected over the convergence zone between snow-covered and bare ground. However, the $12-\mathrm{km}$ grid spacing used in the study mandated the use of a convective parameterization which adds uncertainty to fidelity of the simulated convective response.

To more closely examine the response of orographic convection to snow cover, this study uses convection-permitting numerical simulations to address how changes in snow cover and soil moisture contribute to changes in convective precipitation over the Rocky Mountains. We hypothesize that reductions in snow cover will lead to strengthened local thermal circulations and reductions in local stability that in turn will lead to increases in convective rainfall.
Section 2 describes the model, experimental configuration, and analysis techniques. Results from these experiments are presented in Sect. 3, with an emphasis placed on changes in diurnal convective precipitation and how surface conditions may affect these changes, via modification of the local thermodynamical environment and thermally driven mesoscale circulations. Lastly, conclusions will be discussed in Sect. 4.

\section{Methodology}

We perform three sets of RCM experiments using version 3.8.1 of the Weather Research and Forecasting (WRF) Model (Skamarock et al. 2008). Model configuration is summarized in Table 1. These experiments include a control run, a run designed to represent a future climate, and an additional run dedicated to isolating the influence of snow cover and soil moisture changes. The domain is centered on the Colorado Rocky Mountains (Fig. 1). The model is initialized and forced on the lateral boundaries using output from a set of continental-scale convection-permitting RCM simulations (CONUS) forced by ERA-interim reanalysis data (Liu et al. 2017). Compared to SNOTEL observation sites and PRISM gridded observations, the CONUS simulations show a persistent positive bias in total May-Oct seasonal precipitation over the Colorado Front Range of approximately 20\% (Liu et al. 2017). This wet bias can partially be attributed to a tendency for the CONUS simulation to initiate precipitation more frequently based on comparison to Stage IV observations (Dai et al. 2017). Further comparison of the CONUS simulation against the Stage IV and SNOTEL observational datasets again show a wet bias but with very good agreement on the timing and propagation of afternoon precipitation over the Rocky Mountains (Scaff et al. 2019). Given the emphasis on surface conditions, the Noah land surface model with multiparameterization options (Noah-MP) is used as it offers a sophisticated multi-layered approach for handling snow cover and vegetation (Niu et al. 2011). Soil moisture is paramaterized by Noah-MP across the top $2 \mathrm{~m}$ of the land surface using four layers that are $0-10,10-40$,
Table 1 WRF configuration for all simulations

\begin{tabular}{ll}
\hline Model parameter & Configuration \\
\hline Time & 0000 UTC 25 March-0000 UTC 1 June (2002-2013) \\
Horizontal grid spacing & $4 \mathrm{~km}$ \\
Initial and lateral boundary conditions & $4 \mathrm{~km}$ continental-scale RCM simulations (Liu et al. 2017) \\
Microphysics & Thompson (Thompson et al. 2004) \\
Radiation & RRTMG (Iacono et al. 2008) \\
Boundary layer & Yonsei University (YSU) (Hong et al. 2006) \\
Cumulus & None \\
Land surface model & Noah-MP (Niu et al. 2011) \\
\hline
\end{tabular}


Fig. 1 WRF regional climate model domain. Elevation from the 4-km model grid resolution is shaded. The two regions contained within the black dashed contours correspond to the domains used for averaging in Figs. 3, 4, 6, 7. The red dashed box transecting the Colorado Front Range corresponds to the region used for spatial averaging in the cross sections in Fig. 12

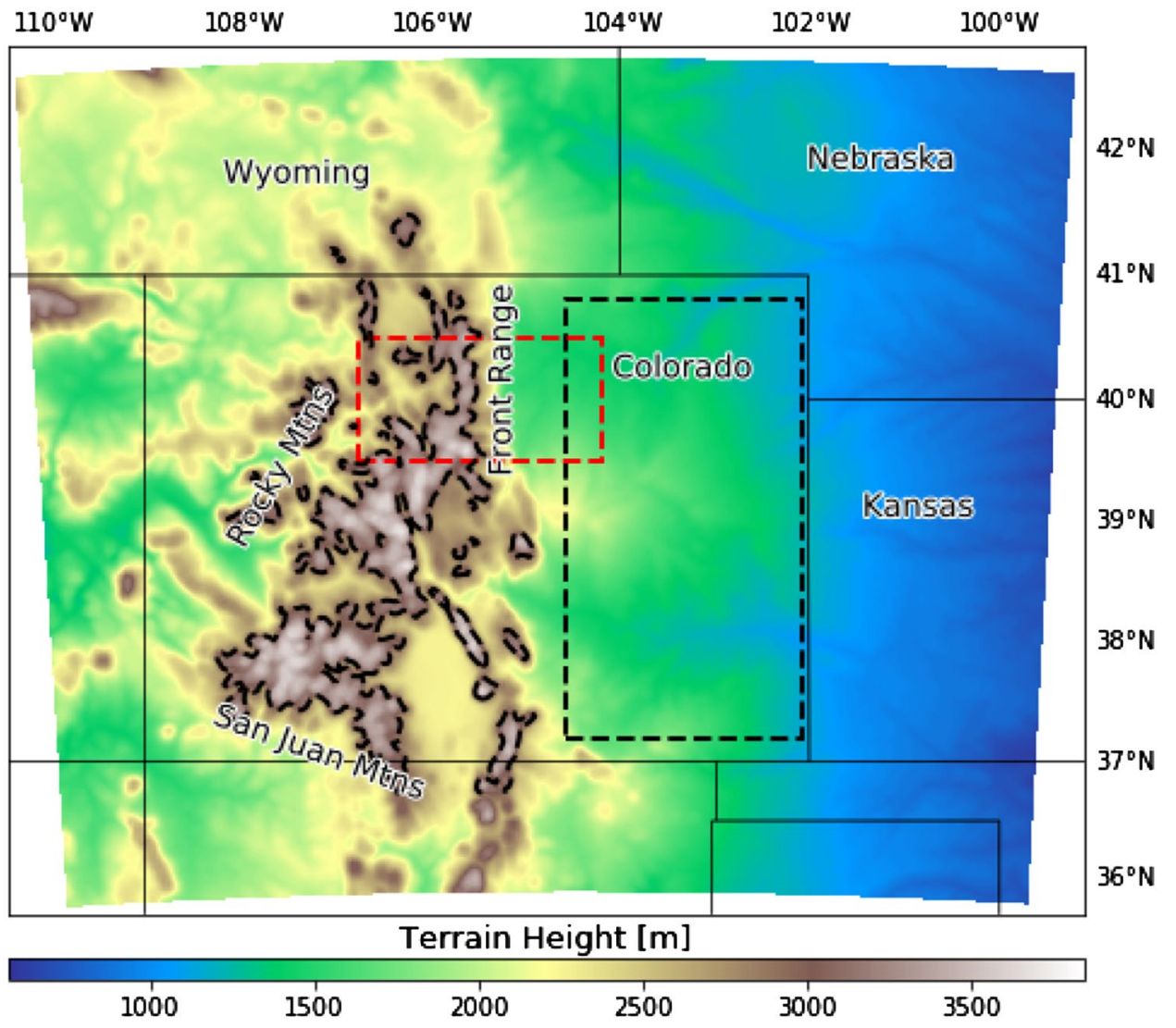

conditions. The advantage of this technique is that it allows for the preservation of synoptic scale patterns, minimizing the change in internal climate variability between simulations, offering an estimate of the potential impacts of climate warming absent of any alterations in the large-scale flow (Schär et al. 1996). Perturbed initial and lateral boundary conditions are acquired from a separate series of CONUS PGW experiments performed by Liu et al. (2017). The perturbations applied to the boundary conditions in the CONUS simulations were derived from the RCP8.5 CMIP5 ensemble monthly mean difference between a 30-years end of century period (2070-2100) and the present (1975-2005). The RCP8.5 scenario (Riahi et al. 2011) is representative of a pathway with high, but plausible, greenhouse gas emissions and radiative forcing, which lead to large end-of-century warming in the CMIP5 ensemble (Collins et al. 2013). The use of this relatively strong forcing contributes to substantial snow loss and snow albedo feedbacks (e.g. Minder et al. 2018) that facilitate the diagnosis of the processes studied here. Actual future snow loss and the corresponding atmospheric response may be weaker if a lower concentration pathway occurs. These climate perturbations varied spatially and were updated monthly. The fields perturbed include temperature, specific humidity, horizontal wind, geopotential, sea surface temperature, sea level pressure, and sea ice. Soil temperature is also perturbed but only during 
the intialization period and is then allowed to freely evolve. Spectral nudging is also employed by Liu et al. (2017) to inhibit any inconsistencies that may occur during longterm simulations. Nudging only occurs above the boundary layer height and only spectral scales of around $2000 \mathrm{~km}$ are nudged. Additionally, to be consistent with the methodology performed in Liu et al. (2017), we adjust the radiative transfer scheme to account for increased concentrations of greenhouse gases including $\mathrm{CO}_{2}, \mathrm{~N}_{2} \mathrm{O}$, and $\mathrm{CH}_{4}$ based on global mean prescribed concentrations for 2085 from the RCP8.5 emissions scenario (Riahi et al. 2007).

A third delta surface experiment (DSURF) is run to isolate the role of surface snow cover and soil moisture changes in modifying orographic convection under climate warming. This experiment uses the same lateral boundary conditions and initial conditions as CTR but artificially fixes the snow water equivalent, snow depth, and soil moisture to be equal to that of the PGW simulation. Soil temperature is not perturbed in DSURF. Instead, it is allowed to evolve interactively in response to the prescribed snow and soil perturbations, consistent with the parameterized physical processes in Noah-MP. These fields are reset at every timestep and the values are updated hourly based on output from CTR. Thus, DSURF simulates the effects of reduced snow cover and altered soil moisture from a future climate state absent the PGW atmospheric forcing. Through comparison of this experiment to CTR, we isolate and quantify the effect these changing land surface variables have on convection.

Additional preliminary work not used in the analysis was performed to gauge model sensitivity to the perturbed variables. A modified DSURF simulation was performed wherein just snow water equivalent and snow depth were perturbed without the soil moisture perturbations. Comparison of these simulations to DSURF showed little change in the overall response due to the inclusion of soil moisture. However, as springtime soil moisture is strongly determined by snowmelt (e.g. Williams et al. 2009), we fixed both soil moisture and snow to maintain consistency.

We limit most of our analysis to days with minimal synoptic forcing so as to better isolate the mesoscale thermal circulations that often help to initiate convection over complex terrain and concentrate on periods most strongly influenced by the land surface. Using an approach similar to that used in Stewart et al. (2002) and Letcher and Minder (2017), days are considered sufficiently synoptically weak if they meet two criteria: the ratio of full model domain averaged downwelling shortwave radiation at the surface is at least $80 \%$ of the clear sky downwelling shortwave radiation at the surface and domain averaged wind speeds at $650 \mathrm{hPa}$ are less than $9 \mathrm{~ms}^{-1}$. This reduces the dataset to 150 days, approximately $20.5 \%$ of the total simulated days, with $10.3 \%$ of the total CTR precipitation over the mountains falling within these days. Days that meet this criteria primarily occur in
May and overall show a more pronounced $500-\mathrm{hPa}$ ridge situated over the western United States with much sparser snow cover and snow depth comapred to April (not shown).

To highlight the dependence of changes in orographic convection on snow loss, spatial averages are calculated for all cells in the Central Rocky Mountains with a terrain height of $3000 \mathrm{~m}$ or greater (black dashed outline over the high-elevation regions in Fig. 1). For comparison of certain quantities, a domain to the east, over the plains, is also selected as representative of the low-elevation response (eastern black dashed box in Fig. 1).

Validation of hourly simulated precipitation is evaluated against Stage IV gridded observational estimates (Lin and Michell 2005) in Sect. 3.2. Stage IV is a quantitative precipitation estimate generated by the National Center for Environmental Prediction based on the NEXRAD Precipitation Processing System and the National Weather Service River Forecast Center precipitation processing. In the western United States, Stage IV can produce large underestimations due to the scarcity of radar observations in complex terrain and limited sampling from surface gauges (Nelson et al. 2016). Additional validation of precipitation and 2-m temperature is done in Appendix 1. Similar to the CONUS model used to initialize and force the lateral boundaries, the CTR demonstrates a wet bias over the plains towards the east of the domain and a persistent cool bias over the topography in central Colorado when compared to several observational datasets.

We determine statistical significance of changes in spatially averaged quantities over the above two analyzed regions using a bootstrapping technique. This is accomplished by creating 10,000 arrays using samples with replacement from an array of daily spatially averaged differences between two simulations. Each array is the same size as the original. The mean of each array is calculated to create a distribution of sample means. We then calculate confidence intervals at the $95 \%$ confidence level for the distribution of sample means using the percentile method outlined in Efron and Gong (1983). If zero falls outside this range, then the mean difference between climate states is considered to be significantly different than zero.

\section{Results}

\subsection{Surface response}

Figure 2 shows an overview of the CTR conditions along with the PGW-CTR and DSURF-CTR differences for snow cover, soil moisture, and 2-m temperature. These are averages of all hourly output for April and May across the 12-years simulation period. There are clear contrasts between the high terrain and plains. In CTR, over the 

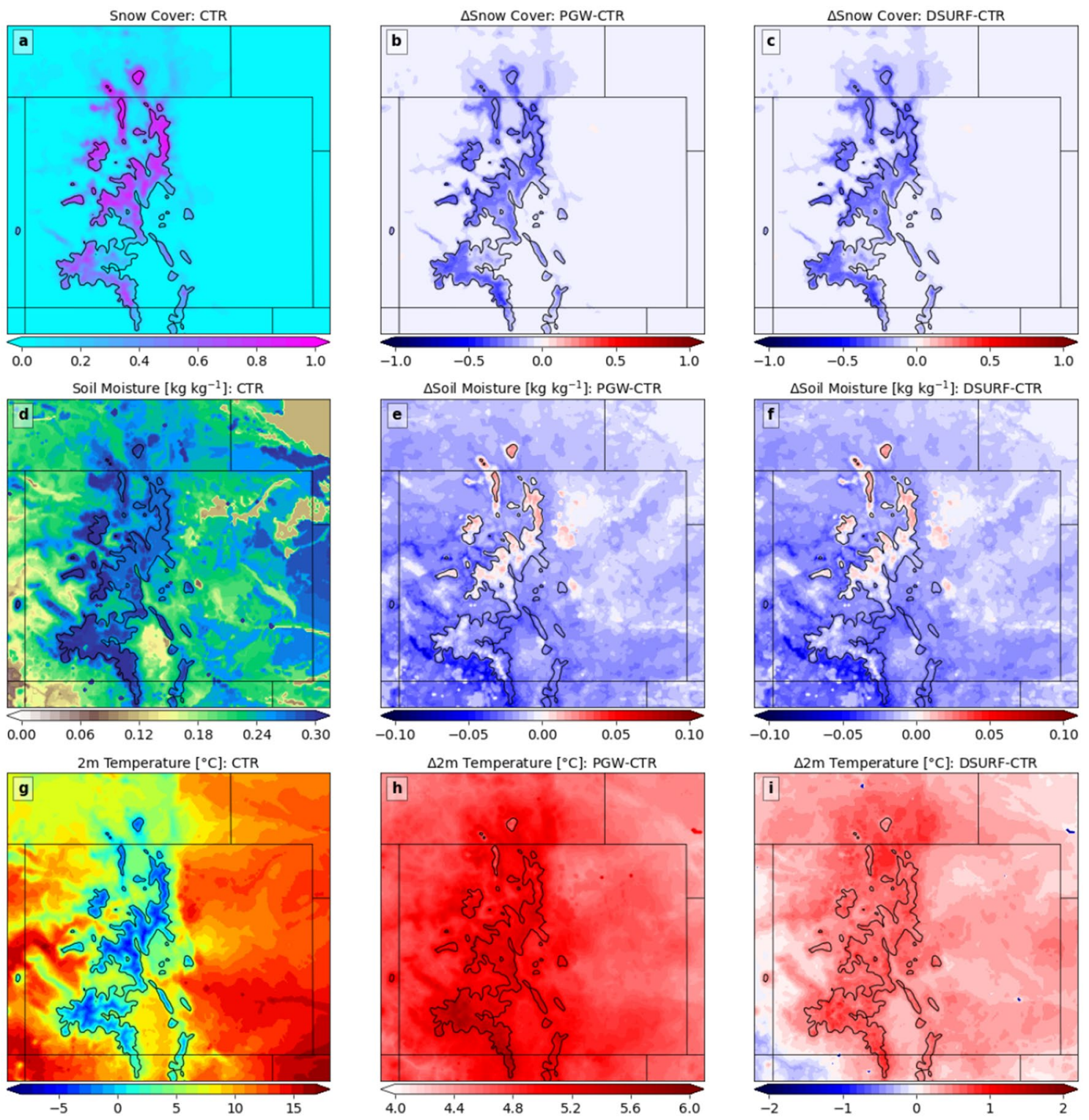

Fig. 2 April and May mean fractional snow-cover, soil moisture at $0.1 \mathrm{~m}$ depth, and 2-m temperature for CTR (a, d, g), PGW-CTR differences $(\mathbf{b}, \mathbf{e}, \mathbf{h})$, and DSURF-CTR differences $(\mathbf{c}, \mathbf{f}, \mathbf{i})$

mountains, cooler temperatures allow for widespread persistent seasonal snowpack that helps to keep soil moisture values high into April and May through insulation and snow melt (Fig. 2a, d, g).

When considering the full climate change response, PGW-CTR, there is a considerable reduction in snow cover for the high terrain (Fig. 2b). This is a result of the perturbed warmer temperatures averaging $5.2^{\circ} \mathrm{C}$ above $3000 \mathrm{~m}$ (Fig. 2h) that act to melt snow quicker and convert snow events to rain events. Additionally, there are reductions in soil moisture for much of the low-elevation regions in the domain (Fig. 2e) likely due to increased evaporation in response to warmer temperatures. Over the mountains, this reduction is muted, and in some areas reversed, because of warmer temperatures causing snow cover to melt sooner in the season and replenish soil moisture. Two-meter temperatures show broad increases for the entire domain in response to the perturbed boundary conditions (Fig. 2h).

In the isolated land surface response, DSURF-CTR, the changes in snow cover and soil moisture are identical to those of the full climate change response by design (Fig. 2c, f). Average warming of $0.56{ }^{\circ} \mathrm{C}$ occurs above $3000 \mathrm{~m}$ where snow loss is greatest and the effects of the SAF are strongest. Even below $3000 \mathrm{~m}$, outside of regions of snow loss, average temperature increases of $0.24{ }^{\circ} \mathrm{C}$ are found likely due to a combination of enhanced sensible heat fluxes due 
to drier soils and advection of air warmed by the SAF over the mountains to low lying regions.

Figure 3 shows the diurnal cycle of near-surface 2-m temperature, specific humidity, and relative humidity for the mountain and plains domains outlined in Fig. 1. At the time of peak temperatures, $1500 \mathrm{MST}$, a warming of $5.8^{\circ} \mathrm{C}$ is found in PGW and $1.0^{\circ} \mathrm{C}$ in DSURF for the mountain domain (Fig. 3a). For comparison, over the plains there is warming of 5.0 and $0.3{ }^{\circ} \mathrm{C}$ respectively at the same time (Fig. 3b). This stronger regional warming over the mountains in the PGW simulation can be attributed to enhanced warming due to snow reductions as shown in DSURF.

2-m specific humidity $\left(\mathrm{q}_{v}\right)$ shows increases of $1.2 \mathrm{~g} \mathrm{~kg}^{-1}$ at 1500 MST over the mountains within the PGW response (Fig. 3c). A stronger moistening is found over the plains with an increase of $2.0 \mathrm{~g} \mathrm{~kg}^{-1}$ at the same time (Fig. 3d). For both regions, this moistening is inherited from the perturbed boundary conditions of the PGW experiment. For the DSURF response at 1500 MST, there is a reduction of $0.2 \mathrm{~g} \mathrm{~kg}^{-1}$ present in both domains. Over the plains, this may be caused by reduced soil moisture (Fig. 2f), which limits evaporation, and reduces near-surface humidity while over the mountains, where soil moisture changes vary in sign, it is less clear what may be driving these changes. Both experiments show reductions in near-surface relative humidity (RH) over the mountains of $7.4 \%$ and $4.7 \%$ at 1500 MST for the PGW and DSURF respectively (Fig. 3e) while only minimal changes in RH are shown over the plains (Fig. 3f). In the PGW case, the reduction in RH over the mountains occurs despite increases in the 2- $\mathrm{m} \mathrm{q}_{v}$, indicating that the near-surface warming outpaces surface moistening. The DSURF simulation similarly shows reductions in RH, though in this case RH reductions coincide with reductions in $\mathrm{q}_{v}$ and increases in temperature. This can be attributed to a combination of strong surface warming and drying associated with extensions in boundary layer height. This latter mechanism is discussed further in Sect. 3.4.

An examination of the surface energy budget is presented in Fig. 4. Similar to the changes in Fig. 3, changes in the surface radiation budget are more prominent over the mountains compared to the plains. Over the mountains, for both PGW and DSURF, reductions in albedo from reduced snow cover increase net shortwave radiation at the surface by $58 \mathrm{~W} \mathrm{~m}^{-2}$ at 1300 MST (Fig. 4a). This contributes to enhanced surface warming and an increase in the net emitted longwave radiation at the surface of $10 \mathrm{~W} \mathrm{~m}^{-2}$ for the same time (Fig. 4c). To balance the large increase in net radiation at the surface, the PGW-CTR mountain difference shows increases in both surface latent and sensible heat fluxes of $37 \mathrm{~W} \mathrm{~m}^{-2}$ and 19 $\mathrm{W} \mathrm{m}^{-2}$ respectively (Fig. 4e, g). Warmer atmospheric temperatures strengthen evaporation which enhances the surface latent heat flux. Similarly, the warmer surface also acts to enhance upward sensible heat fluxes. Bowen ratios for PGW are reduced by 0.4 over the mountains and 0.03 over the plains, indicating an increased importance of turbulent latent versus sensible heat fluxes. The DSURF-CTR difference over the mountains shows increases in the sensible heat flux of $40 \mathrm{~W} \mathrm{~m}^{-2}$ at $1300 \mathrm{MST}$ and minimal changes in latent heat flux. The Bowen ratio for DSURF is increased by 0.28 over the mountains and 0.32 over the plains. Without the warmer atmospheric temperatures present in PGW, latent heat fluxes are not nearly as enhanced in DSURF despite the identical soil moisture fields. As such, the warmer surface releases a larger proportion of sensible heat relative to
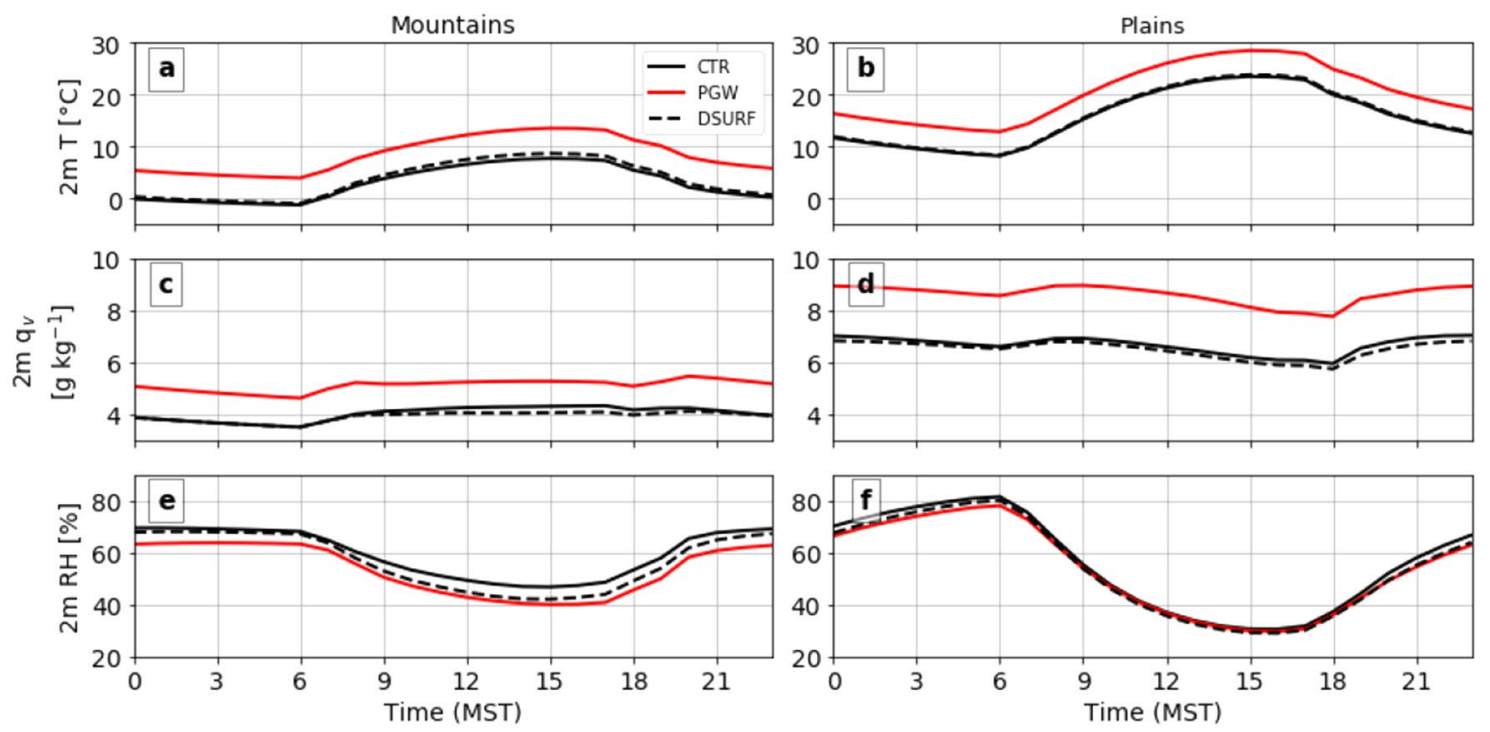

Fig. 3 April and May mean diurnal cycle for 2-m temperature $(\mathrm{T})(\mathbf{a}, \mathbf{b}), 2-\mathrm{m}$ specific humidity $\left(\mathrm{q}_{v}\right)(\mathbf{c}, \mathbf{d})$, and 2-m relative humidity $(\mathrm{RH})(\mathbf{e}, \mathbf{f})$ for the mountain and plains domains in Fig. 1 

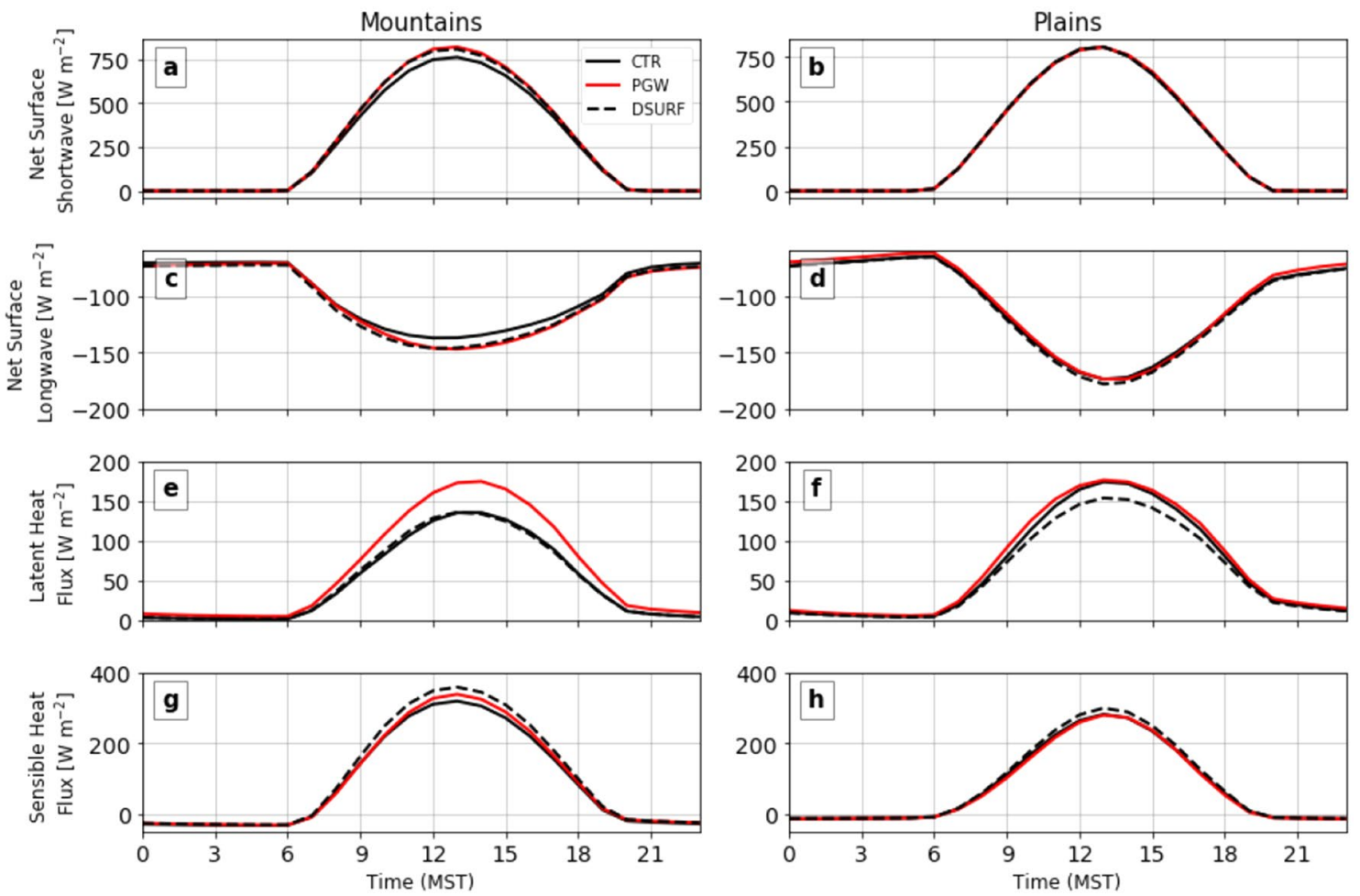

Fig. 4 April and May mean diurnal cycle for net surface shortwave radiation $(\mathbf{a}, \mathbf{b})$, net surface longwave radiation $(\mathbf{c}, \mathbf{d})$, latent heat flux $(\mathbf{e}, \mathbf{f})$, and sensible heat flux $(\mathbf{g}, \mathbf{h})$ for the mountain and plains

latent heat. Over the plains, there are only modest PGWCTR changes in the surface energy budget partitioning while DSURF-CTR changes are much closer to those found over the mountains. DSURF shows small increases in net emitted longwave and an increase in surface sensible heat flux (Fig. 4h) while the latent heat flux is reduced by $20 \mathrm{~W} \mathrm{~m}^{-2}$ at 1300 MST (Fig. 4f) likely due to reduced soil moisture.

\subsection{Convective response}

Figure 5a-c shows the accumulated precipitation and differences between experiments. In CTR, the greatest accumulations are found over the high terrain, especially over the western slopes where synoptic westerlies are mechanically lifted (Fig. 5a). Similarly large accumulations are found east of the high terrain, likely due to eastward-propagating orographic convection. The full PGW-CTR climate change response is spatially varied with reductions in precipitation accumulation over the western slopes contributing to an average reduction of $172 \mathrm{~mm}$ for the mountains (Fig. 5b). As shown in Fig. 5e, these large reductions disappear when days with strong synoptic forcing are removed from the analysis. We believe these alterations in total precipitation shown in Fig. 5b can possibly be explained by modifications of mechanically lifted air on the westward slopes. While this domains outlined in Fig. 1. Radiative fluxes are defined as positive downwards while turbulent fluxes are defined as positive upwards

non-convective response falls outside of the scope of this paper, these precipitation reductions may be due in part to this drying of the surface and raising of the lifted condensation level (LCL). West of the mountains, LCLs increase by 200-260 m (not shown). Additionally, Fig. 2e shows concentrated reductions in soil moisture southwest of the San Juan mountains and, to a lesser extent, east of the Rocky Mountains. In the DSURF-CTR isolated land surface response (Fig. 5c), the mountain response differs from PGW and shows an increase in accumulated precipitation of a similar magnitude that is closely tied to the terrain, suggesting that the atmospheric response to land surface changes helps to mitigate precipitation reductions that occur in the full PGW response.

Figure $5 d-f$ show results for days with minimal synoptic influence, using the filtering criteria described in Sect. 2, which are hereafter referred to as synoptically filtered days. Here, the regions of maximum precipitation accumulation are shifted east (Fig. 5d). Under weak synoptic forcing, the role of mechanical lifting on the western slopes is reduced and convection tends to initiate over the high terrain and propagate eastward under weak westerly flow. This leeside shift of precipitation accumulation with weakening synoptic influence is consistent with results from Jing et al. (2018) who note a higher prevalence for stratiform 

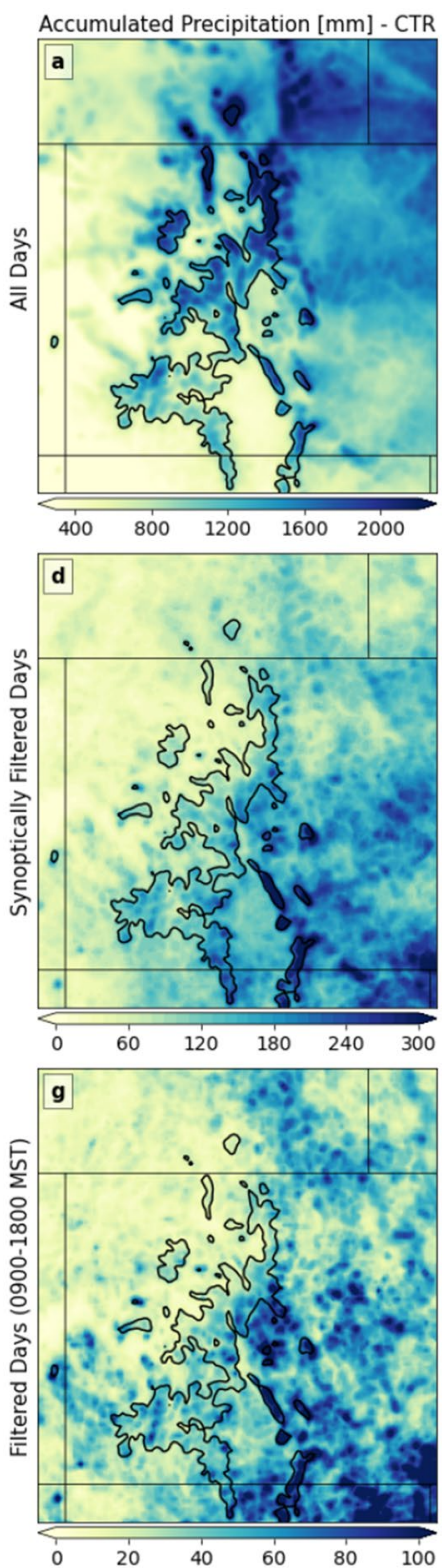
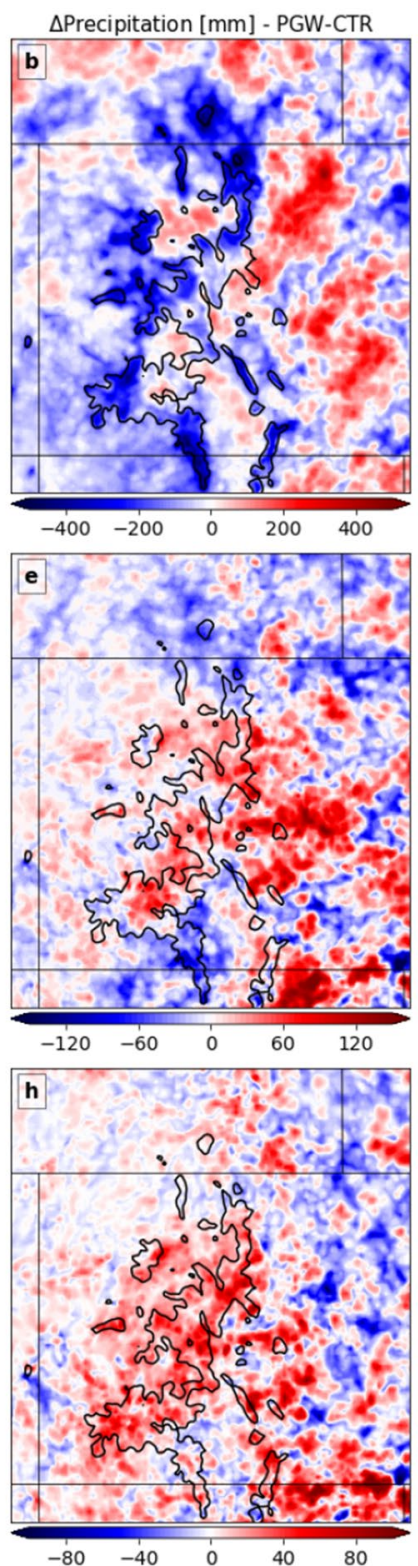
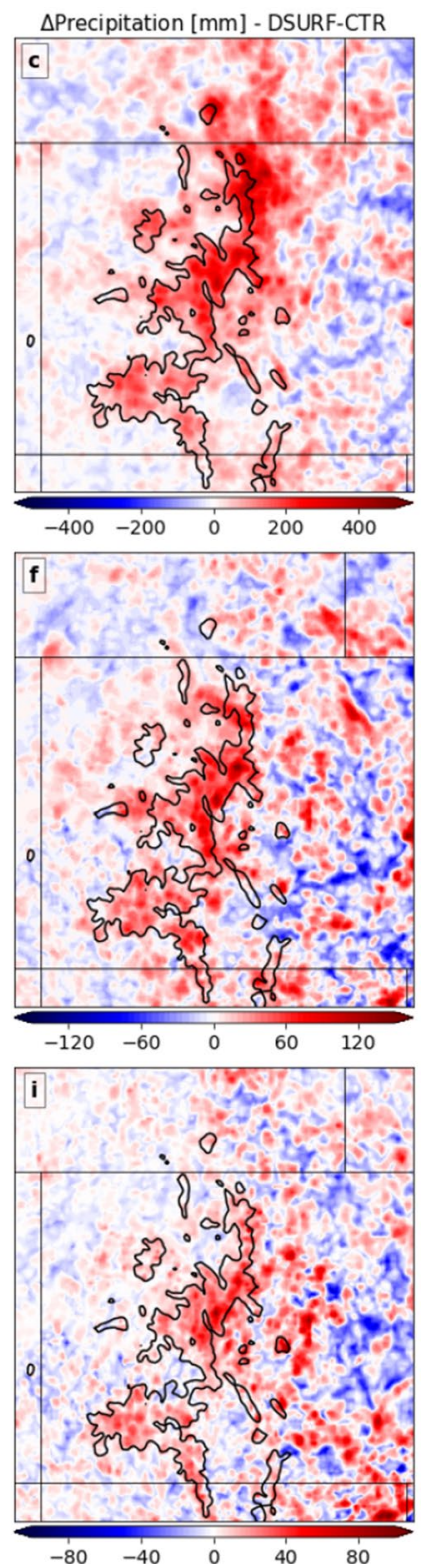

Fig. 5 April-May precipitation plots for: (a-c 12-years total accumulated precipitation, (d-f synoptically filtered total accumulated precipitation, and $\mathbf{g}-\mathbf{i}$ synoptically filtered daytime total accumulated precipitation from 0900 to 1800 MST for CTR (a, d, g), PGW-CTR difference $(\mathbf{b}, \mathbf{e}, \mathbf{h})$, and DSURF-CTR difference $(\mathbf{c}, \mathbf{f}, \mathbf{i})$

and land-atmosphere interactions are expected to be strongest. During these hours a PGW-CTR increase emerges over much of the high terrain (Fig. 5h), which was otherwise obscured by decreases in nocturnal precipitation. The spatial pattern of the DSURF-CTR response is not significantly affected when limiting the analysis to daytime precipitation accumulation though the amount of precipitation is lessened due to the shorter time window considered (Fig. 5i).

In order to understand the diurnal nature of these changes in precipitation, the average diurnal cycle of precipitation rate is presented in Fig. 6a for both the simulations and Stage to focus on the times when thermally driven circulations 
Fig. 6 Diurnally averaged time series within the mountain domain outlined in Fig. 1 for a total precipitation, b synoptically filtered total precipitation, c synoptically filtered cloud liquid water path, and $\mathbf{d}$ synoptically filtered cloudy updraft strength for CTR (solid black), PGW (solid red), and DSURF (dashed black). Red (PGWCTR) and black (DSURF-CTR) dots are representative of hours where mean differences deviate from zero at $95 \%$ confidence
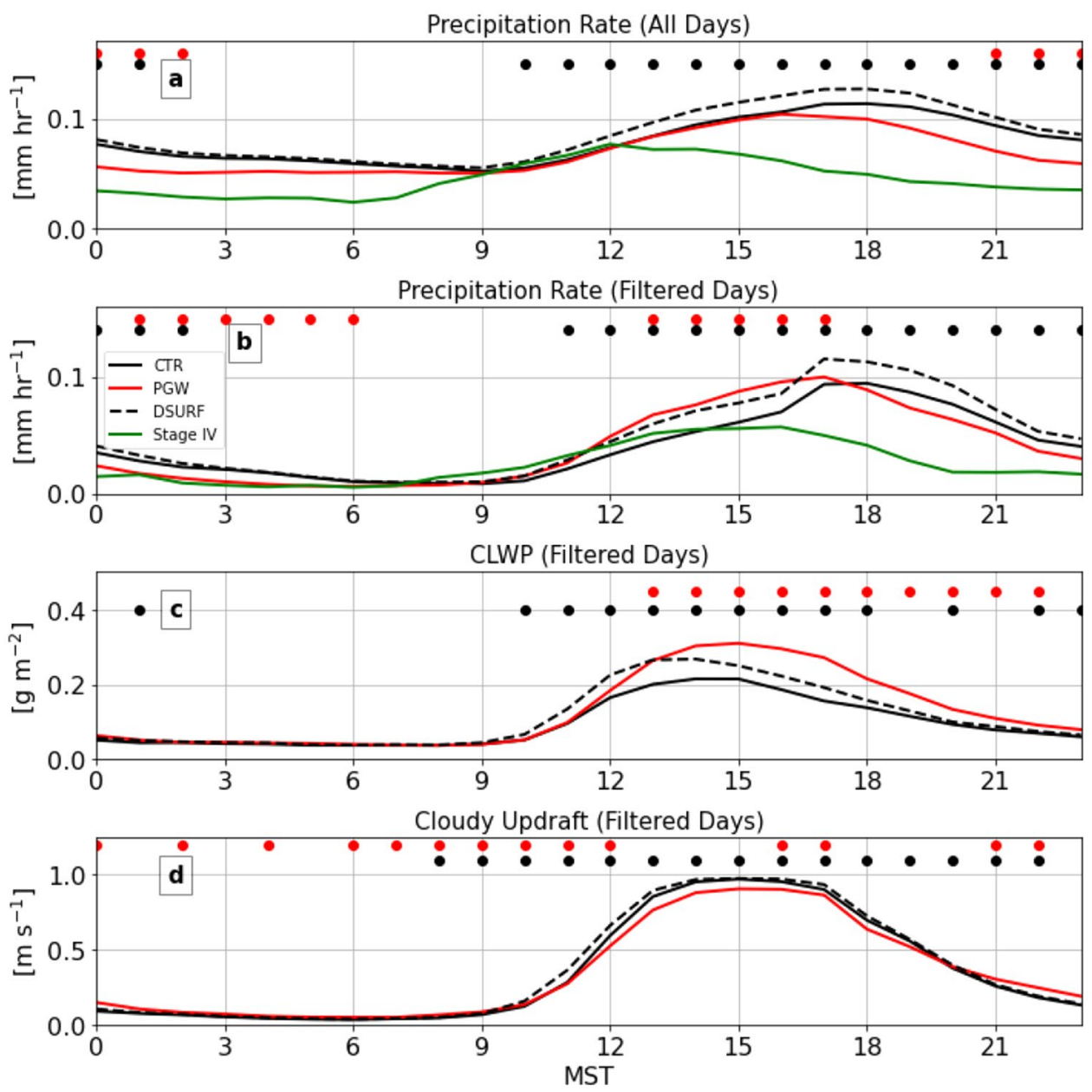

IV data. The CTR simulated diurnal cycle of precipitation is consistent with prior observational studies over the Rockies, showing convective activity building throughout the day and peaking in the afternoon hours (Wallace 1975; Carbone and Tuttle 2008). However, it disagrees with the timing and intensity of Stage IV observations. Stage IV shows an earlier peak in precipitation around 1200 MST while the simulated precipitation does not peak until around 1800 MST. Furthermore, Stage IV has a lower peak intensity of $0.077 \mathrm{~mm} \mathrm{~h}^{-1}$ compared to $0.113 \mathrm{~mm} \mathrm{~h}^{-1}$ in the CTR.v

The PGW simulation shows no statistically significant changes relative to CTR during the daytime from 0900 to 1600 MST with most of the reduction in hourly precipitation occurring in the late afternoon and overnight. In contrast, DSURF shows a statistically significant increase in hourly precipitation starting at 1000 MST and extending until 0100 MST with a peak increase of $0.015 \mathrm{~mm} \mathrm{~h}^{-1}$ at $1600 \mathrm{MST}$.

Results are shown for synoptically filtered days in Fig. 6 b. Precipitation on these days is dominated by diurnal convection and is almost entirely absent in the late night and early morning hours (0000-0800 MST). Here, Stage IV more closely matches the CTR simulation during the morning and early afternoon hours though the peak intensity is $2 \mathrm{~h}$ earlier and lower by $0.037 \mathrm{~mm} \mathrm{~h}^{-1}$. Relative to CTR, both the PGW and DSURF simulations have similar statistically significant increases in daytime precipitation rates of $43.7 \%$ and $29.37 \%$ averaged from 1300 to 1600 MST, suggesting that land surface changes are contributing to increases in afternoon convective rains in the full PGW response. The DSURF increases are statistically significant across a much broader time period (1100-0200 MST). Furthermore, the PGW simulations show significant reductions in nocturnal precipitation from about 0100 to 0600 MST which act to partially balance the increases in daytime precipitation.

To test for changes in convective cloud properties, Fig. 6c shows the average diurnal cycle for cloud liquid water path (CLWP). In CTR, the diurnal cycle of CLWP is similar to that of hourly precipitation accumulation, though it peaks earlier in the day since convective cloud development precedes precipitation. For both the PGW and DSURF simulations, significant increases in hourly CLWP are simulated throughout much of the day relative to CTR. The timing of the peak differences vary, occurring around 1500 MST for PGW and 1300 MST for DSURF. The timing of these 
maximum changes in CLWP precede the peak time for precipitation, consistent with changes in cloud properties during the early stages of convective development.

To test for changes in the strength of convective motions, we plot a time series of cloudy updraft strength in Fig. $6 \mathrm{~d}$. Grid-points containing upward motion and cloud water mixing ratio values exceeding $0.1 \mathrm{~g} \mathrm{~kg}^{-1}$ are classified as "cloudy updrafts". Their vertical velocities are vertically averaged to produce a two-dimensional field of cloudy updraft strength. Using a cloud water threshold that varies $50 \%$ in either direction does not significantly change the result. Cloudy updraft strength shows similar timing to that of CLWP with peak intensities occurring around 1500 MST. In the PGW simulation, there are moderate reductions in cloud updraft strength, maximizing at $-0.09 \mathrm{~m} \mathrm{~s}^{-1}$, primarily from 1200 to 1500 MST. This suggests that PGW increases in CLWP and convective precipitation are not driven by more vigorous ascent. The DSURF simulation shows slight increases, maximizing at $0.08 \mathrm{~m} \mathrm{~s}^{-1}$, in cloudy updraft strength from 1000 to $1400 \mathrm{MST}$ and minimal changes during the period of strongest ascent. These increases in updraft strength may contribute somewhat to increases in CLWP and precipitation, particularly in the morning hours. However, since they are modest and do not persist into the afternoon, they are unlikely to be the primary cause of increased convective precipitation in DSURF.

We further break down the convective precipitation response into changes in the frequency and intensity for synoptically filtered days in Fig. 7. Precipitation frequency is represented by the percent of grid cells within the mountain and plains boxes in Fig. 1 with non-zero surface precipitation while precipitation intensity is the average hourly precipitation rate excluding cells where there was no hourly accumulated precipitation. Despite similar magnitude increases in total precipitation, the response of precipitation frequency for the mountains is of opposite sign for PGW and DSURF when compared to CTR.
DSURF shows increases in precipitation frequency from 0900 until 0200 MST while PGW shows reductions in precipitation frequency for every hour. This PGW reduction is minimized during the daytime when the largest increases are found in DSURF, suggesting that the land surface response acts to mitigate reductions in precipitation frequency. This is further supported by looking at the change in PGW precipitation frequency over the plains in Fig. 7b. The lack of any strong surface forcing over the plains removes this ability for the surface to modulate precipitation frequency, notably from 1100 to $1700 \mathrm{MST}$, and results in larger decreases in frequency.

For precipitation intensity over the mountains, DSURF shows small increases, peaking during the evening hours. In contrast, PGW shows a much stronger increase in daytime precipitation intensity within the same time period, with the largest increases occurring during the early to mid afternoon hours. Thus, for DSURF, increases in both the frequency and intensity of convective precipitation are working together to increase convective precipitation. In contrast, PGW shows reductions in frequency overcome by increases in intensity during the daytime, indicating that the daytime precipitation increases are due to larger precipitation intensity. During the overnight hours, the absence of any increases in precipitation intensity allows for reduced nocturnal precipitation solely due to lower frequency of occurrence. Over the plains, PGW also shows increases in precipitation intensity that maximize during the day at 1700 MST, with a secondary peak occurring overnight. Unlike the mountains, the DSURF precipitation intensity and frequency over the plains shows no strong response owing to the lack of any significant changes to the land surface for this region to drive these changes. Next, we examine the mechanisms responsible for changes in convective precipitation, first focusing on changes in the thermodynamic environment and then on changes in mesoscale circulations.
Fig. 7 Diurnally averaged time series for synoptically filtered days within the mountain domain $(\mathbf{a}, \mathbf{c})$ and plains domain $(\mathbf{b}, \mathbf{d})$ in Fig. 1 for $(\mathbf{a}, \mathbf{b})$ precipitation frequency and $(\mathbf{c}, \mathbf{d})$ precipitation intensity for CTR (solid black), PGW (solid red), and DSURF (dashed black) simulations
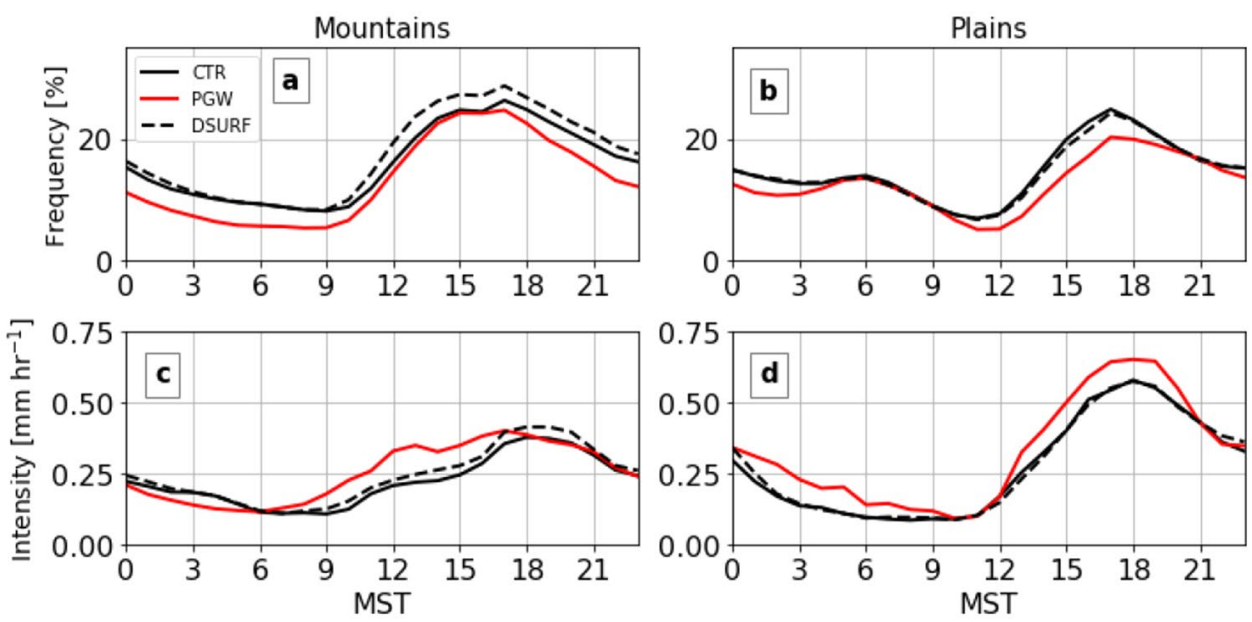


\subsection{Thermodynamic mechanisms}

To investigate changes in aspects of the thermodynamic environment that may influence convection, Fig. 8 shows maximum convective available potential energy (MCAPE), convective inhibition for the most unstable parcel (MCIN), lifting condensation level corresponding to the most unstable parcel (LCL), and precipitable water within the lowest 12 model levels approximating the boundary layer height

Fig. 8 Synoptically filtered April and May mean MCAPE (a), $\triangle \mathrm{MCAPE}(\mathbf{b}, \mathbf{c}), \mathrm{MCIN}$ (d), $\triangle \mathrm{MCIN}(\mathbf{e}, \mathbf{f}), \mathrm{PWAT}_{P B L}$ (g), $\triangle \mathrm{PWAT}_{P B L}(\mathbf{h}, \mathbf{i}), \mathrm{LCL}$ $(\mathbf{j})$, and $\triangle \mathrm{LCL}(\mathbf{k}, \mathbf{l})$ averaged between 0800 and 1200 MST. Columns are organized by CTR (left), PGW-CTR (center), and DSURF-CTR (right)
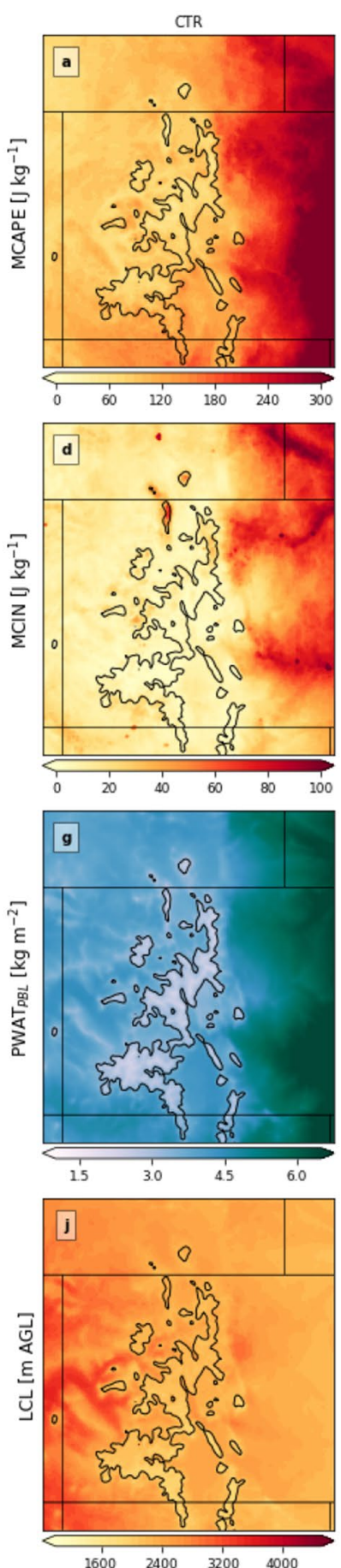

over high terrain (1.5-1.7 km AGL) $\left(\mathrm{PWAT}_{P B L}\right)$. MCAPE, MCIN, and LCL are calculated using parcels that begin at the maximum equivalent potential temperature level within the lowest $3000 \mathrm{~m}$ AGL. These fields are averaged between 0800 and 1200 MST to represent the pre-convective environment. In CTR, contrasts between the highest elevation regions and the plains are present for all fields. Over the high terrain, MCAPE averages to $85 \mathrm{~J} \mathrm{~kg}^{-1}$ while the average over the eastern plains is much larger at $356 \mathrm{~J}$
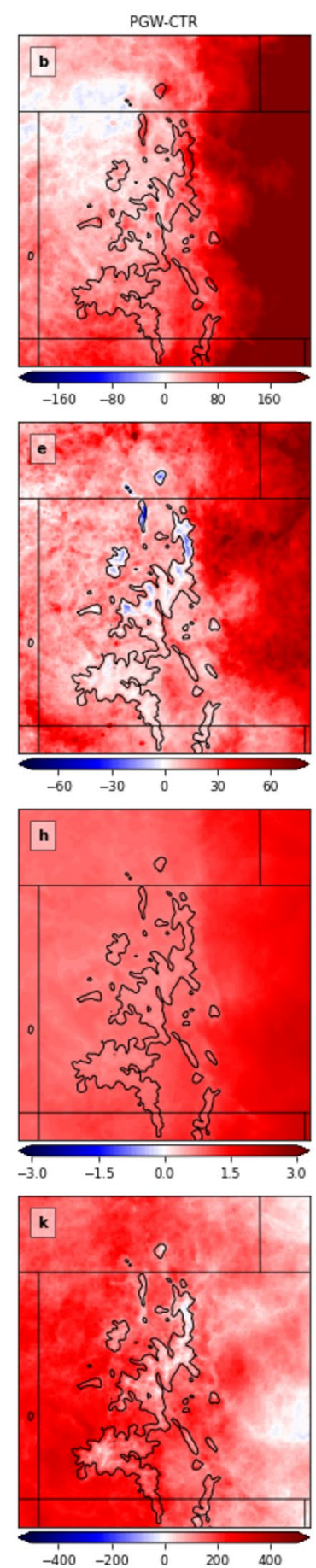
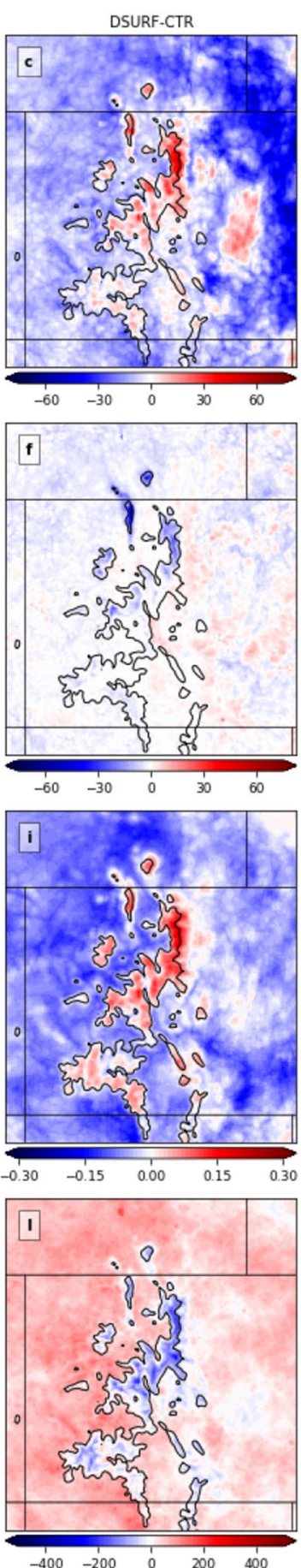
$\mathrm{kg}^{-1}$ (Fig. 8a). MCIN values over the high terrain are also small, averaging to $8 \mathrm{~J} \mathrm{~kg}^{-1}$, relative to average values of $78 \mathrm{~J} \mathrm{~kg}^{-1}$ over the plains (Fig. 8d). Over the mountains, a combination of cooler temperatures and persistent snow cover act to limit the amount of energy available for convection. In contrast, the eastern plains are warmer and moister owing to the lower elevation and snow free ground in addition to a larger amount of available moisture due to southerly advection. PWAT $\mathrm{PBL}_{P B}$ at high elevations is typically lower, averaging at $2.9 \mathrm{~kg} \mathrm{~m}^{-2}$, relative to values over the plains, averaging at $6.5 \mathrm{~kg} \mathrm{~m}^{-2}$ (Fig. $8 \mathrm{~g}$ ). LCLs over the mountains and plains are comparable, with heights averaging $2110 \mathrm{~m}$ AGL (Fig. 8j).

When considering the climate change response, the contrast between the higher and lower elevations persists. The PGW-CTR difference for MCAPE, MCIN, and PWAT ${ }_{P B L}$ all show large increases east of the terrain (Fig. 8b, e, h). The large-scale warming and moistening of the troposphere associated with the PGW forcing are the primary cause of these changes, as shown by Rasmussen et al. (2017). Additionally, Chen et al. (2020) show a similar PGW response for CAPE and CIN across the CONUS and directly attribute the increases in both quantities to higher atmospheric specific humidity concentrations. Similarly, this warming and moistening can also help to explain the large increases in PGW precipitation intensity that occurs over both the mountains and plains despite different surface forcings (Fig. 7d). This overall warmer and moister near-surface environment drives increases in MCAPE through surface destabilization. Additionally, the vertical profile of PGW-CTR $\Delta \mathrm{T}$ maximizes at $6{ }^{\circ} \mathrm{C}$ in the mid to lower troposphere $(6000 \mathrm{~m})$ which acts to further increase MCIN through a strengthening of lower tropospheric stratification. In addition to strengthening MCIN, this enhanced stratification can also help to explain reductions in precipitation frequency found over the mountains for PGW (Fig. 7b). Over the high terrain, smaller total changes are found, associated with the lower amount of MCIN present over this region in CTR. LCL increases across most of the domain with the largest increases found west of the San Juan Mountains (Fig. 8k), corresponding to regions with large reductions in soil moisture. Substantial drying and surface warming (Fig. 3e, f) lead to increases in the near-surface dewpoint depression and explain these increases in LCL. MCAPE and PWAT ${ }_{P B L}$ also show large increases for most of the domain with the largest values east of the terrain.

The DSURF response shows a contrasting signal between the mountains and plains. DSURF MCAPE increases maximize at $51 \mathrm{~J} \mathrm{~kg}^{-1}$ relative to CTR over the high terrain and decreases by a similar magnitude over the eastern low elevation portions of the domain (Fig. 8c). Much of the domain exhibits minimal changes in MCIN with only minor reductions in the northern portions of the high terrain (Fig. 8f). Over the mountains, the small MCIN values found in CTR (Fig. 8d) place a limit on potential MCIN reductions. PWAT $_{P B L}$ differences show a sharp contrast between the mountains and plains. High-elevation regions exhibit increases maximizing at $0.17 \mathrm{~kg} \mathrm{~m}^{-2}$ while the plains show a mixed response that skews negative ranging from -0.18 to $0.06 \mathrm{~kg} \mathrm{~m}^{-2}$ (Fig. 8i). These patterns in the PWAT $_{P B L}$ differences contribute to similar changes in LCL that vary with elevation. The moistening of the PBL over the mountains prompts reductions in LCL as large as $302 \mathrm{~m}$ with a mean reduction of $38 \mathrm{~m}$ while low elevation regions with no clear moistening signal see mean increases of $37 \mathrm{~m}$ concentrated west of the terrain (Fig. 81).

The contribution of the land surface to the overall response can be determined through consideration and comparison of the DSURF and PGW convective indices. Over the plains, the DSURF reductions in MCAPE and PWAT ${ }_{P B L}$ in addition to the increase in LCL are consequences of reduced soil moisture inhibiting the amount of available moisture at the surface (Figs. 2f, 3d) and the absence of any significant warming (Fig. 3b). The mechanisms driving DSURF-CTR changes in MCAPE, PWAT ${ }_{P B L}$, and LCL over the high terrain are less clear. Surface warming associated with the SAF (Fig. 3a) can act to destabilize the environment through steeper lapse rates that result in higher MCAPE. However, the cause of the moistening needed to explain increases in PWAT $_{P B L}$ and reductions in LCL is less clear given the reductions in near-surface $\mathrm{q}_{v}$ and $\mathrm{RH}$ (Fig. 3) along with the lack of significant changes to the surface latent heat flux (Fig. 4). While 2-m variables indicate a drying near the surface, PWAT $_{P B L}$ increases over the high terrain indicate increases in moisture within the PBL as a whole. When the max level of equivalent potential temperature is above the surface, this increase in PBL humidity can contribute to increased MCAPE and decreased LCL, and in turn increased convective precipitation. As established previously, over regions of high terrain, large accumulations of sensible and latent heat can be attributed to transport via thermally driven circulations (e.g., Kimura and Kuwagata 1995; Sato and Kimura 2005). Below we argue that transport of moisture by enhanced orographic thermal circulations can help to explain the simulated moistening and increase in convective precipitation.

\subsection{Dynamic mechanisms}

We next investigate how changes in mesoscale thermally driven circulations may influence the convective response, starting with an analysis of the $10-\mathrm{m}$ winds. In Fig. 9 the synoptically filtered mean winds for 1000,1200 , and 1400 MST are compared. In the 

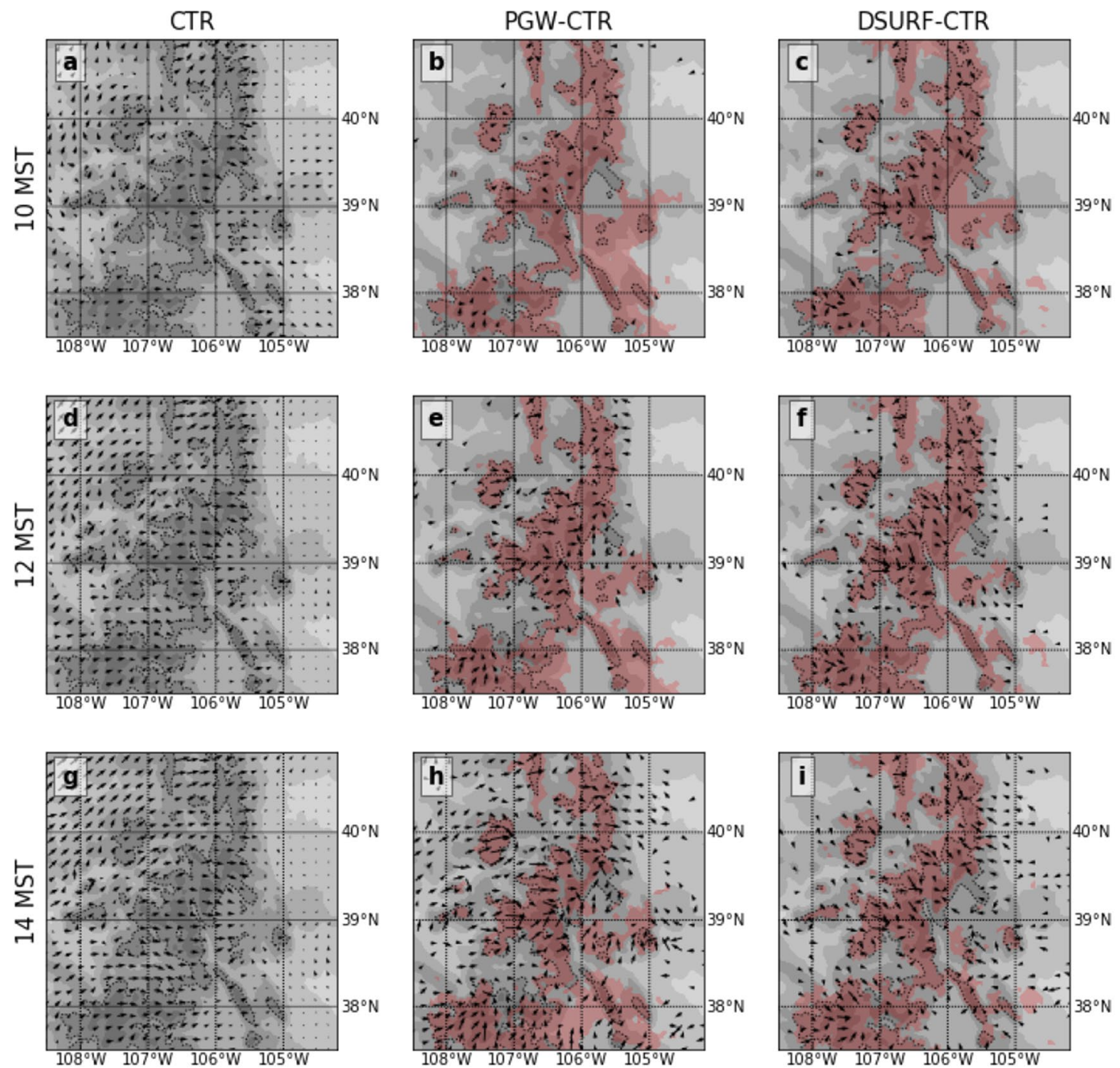

Terrain Height (m)

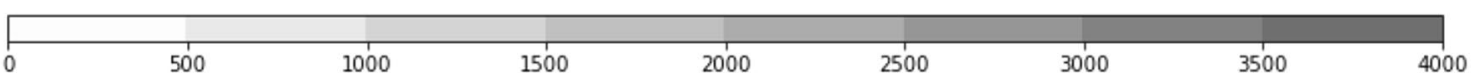

Fig. 9 Synoptically filtered April and May mean 10-m vector winds averaged at $1000(\mathbf{a}-\mathbf{c}), 1200(\mathbf{d}-\mathbf{f})$, and $1400(\mathbf{g}-\mathbf{i})$ MST. Columns are organized by CTR $(\mathbf{a}, \mathbf{d}, \mathbf{g})$, PGW-CTR $(\mathbf{b}, \mathbf{e}, \mathbf{h})$, and DSURFCTR (c, f, i). Difference plots show only windspeed differences

CTR, westerly background flow develops and organizes as the day progresses (Fig. 9a, d, g). This flow stops at the eastern extent of the high terrain and transitions to a much weaker flow over the plains. In response to SAF-enhanced warming over the high terrain, both the PGW (Fig. 9b, e, h) and DSURF (Fig. 9c, f, i) simulations show an increase in easterly winds over the plains directed towards the high terrain becoming stronger as the day progresses. There is a similar upslope increase in westerly winds west of the highest terrain. Both greater than $0.3 \mathrm{~m} \mathrm{~s}^{-1}$. The upper decile of surface warming is shown in red shading. Terrain elevation is shaded. The 3000-m elevation contour is denoted with a dotted line

changes in the $10-\mathrm{m}$ wind field are directed towards the regions that experience the greatest surface warming and indicate an increase in convergence along the mountain ridgeline. This is similar to the mesoscale airflow response to the SAF found in Letcher and Minder (2017).

To examine how these wind patterns may influence mesoscale uplift and convective initiation, we quantify the horizontal mass flux convergence (MFC) of these nearsurface winds defined here as: 
$M F C=-\nabla_{h} \cdot \int_{p_{0}}^{p_{1}} \frac{\mathbf{v}_{h}}{g} d p$

where $\mathbf{v}_{h}$ is horizontal windspeed, and $\mathrm{p}_{0}$ and $\mathrm{p}_{1}$ is pressure corresponding to the lowest model grid (approximately $2 \mathrm{~m}$ AGL) and the 10th vertical grid level (approximately $1050 \mathrm{~m}$ AGL). Figure 10a shows MFC averaged in the hours generally preceding convective initiation from 1000 to 1200 MST. There exists a dipole pattern with anomalous divergence on the western slopes and anomalous convergence along the eastern slopes. This leeward convergence is associated with stronger westerly synoptic flow meeting upslope thermally driven flow along a convergence boundary on the eastern slope (e.g., Fig. 9a, d). The PGW-CTR difference (Fig. 10b) shows a strengthening of this dipole signature with enhanced divergence and convergence on the western and eastern slopes respectively. Positive westerly wind anomalies are present throughout most of the troposphere in the PGW simulation and act to enhance the leeside convergence when mixed downwards into the mountain boundary layer. The CTR-DSURF difference (Fig. 10c) shows increased convergence largely centered on the highest terrain, associated with strengthened thermally direct flows that converge towards the maxima in SAF induced warming. The lack of any leeward displacement in the convergent response is likely due to the absence of westerly wind changes between the DSURF and CTR simulations. The above-documented enhanced low-level convergence can provide a dynamic lifting mechanism that aids convective development, helping to explain the enhanced convective precipitation.

To examine how these circulations may affect the evolution of low-level humidity, we calculate low-level moisture flux convergence (QFC) as:

$Q F C=-\nabla_{h} \cdot \int_{p_{0}}^{p_{1}} \frac{q_{v} \mathbf{v}_{h}}{g} d p$

where $\mathrm{q}_{v}$ is specific humidity. QFC averaged for the same hours in Fig. 10d shows a very similar pattern to that of MFC in Fig. 10a. PGW changes in QFC (Fig. 10e) are spatially consistent with MFC but show relatively larger increases in convergence along the eastern slopes of the
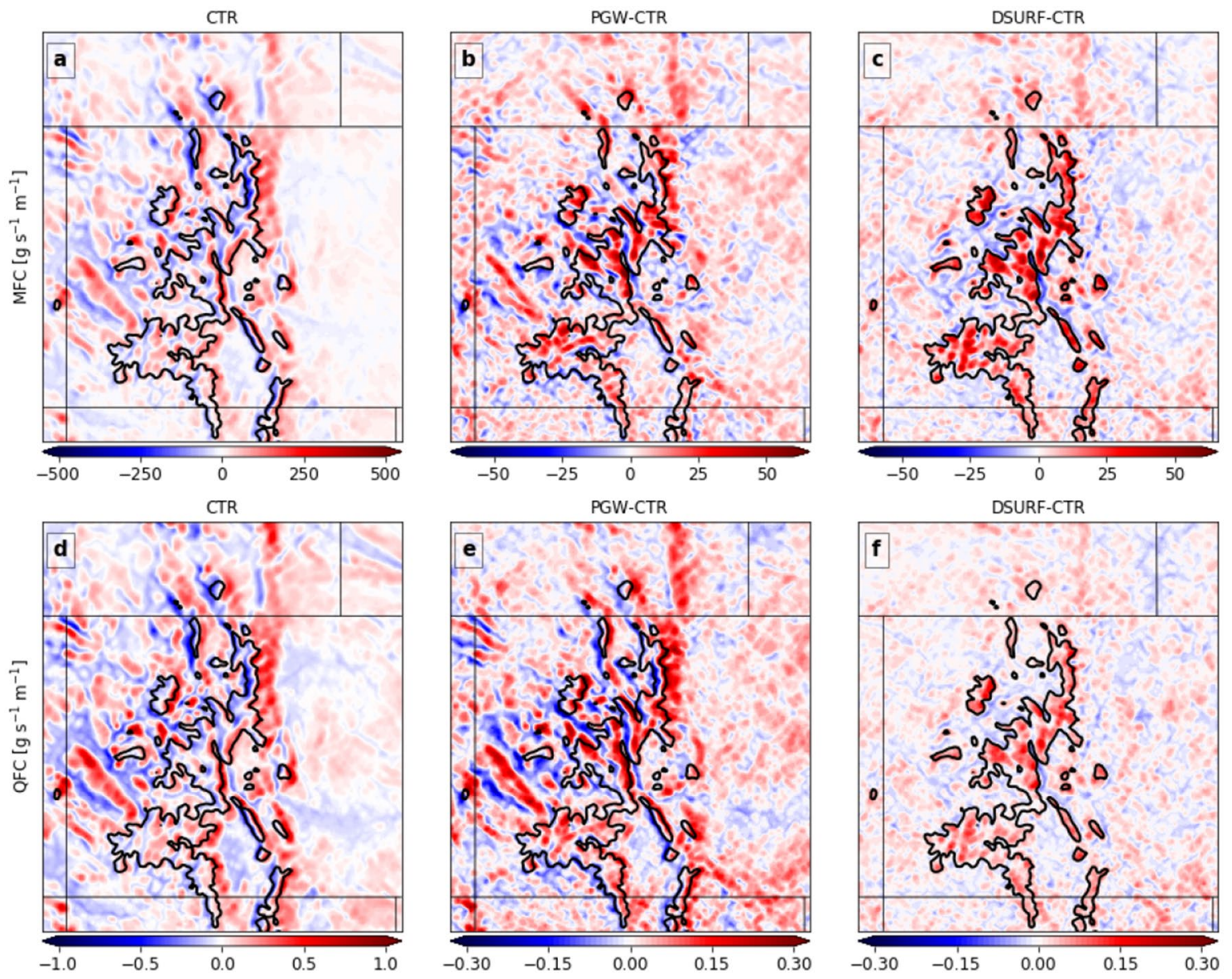

Fig. 10 Synoptically filtered April and May mean mass flux convergence (a-c) and moisture flux convergence (d-f) averaged between 1000 and 1200 MST 
terrain. This enhanced QFC response is due to the inclusion of moisture, which is considerably higher in PGW compared to DSURF and CTR (Fig. 3). DSURF changes (Fig. 10f) show enhanced QFC largely confined to the mountains. This response, through transport of larger amounts of moisture to the high terrain, acts to increase PWAT ${ }_{P B L}$ and lower LCL heights (Fig. 8h, k).

Figure 11 shows the average diurnal cycle of MFC and QFC over the mountains. To include the lee-side convergence zones, we broaden our mountain analysis region to include all cells that have an eastward facing aspect and an elevation greater than $2000 \mathrm{~m}$ in addition to all cells with elevation greater than $3000 \mathrm{~m}$. Figure 11a shows a diurnal pattern of MFC that maximizes around 1200 MST in the CTR and DSURF simulations and around 1400 MST in the PGW simulation. Figure $11 \mathrm{~b}$ shows a similar timing for QFC. The timing of these maxima precedes that of both CLWP and hourly precipitation accumulation for all three simulations, consistent with the convergent circulations contributing to pre-conditioning the convective environment and providing lift to aid in convective initiation. Both the PGW and DSURF simulations show similar increases in daytime MFC beginning at $0900 \mathrm{MST}$ and maximizing close to 1300 MST. The similar magnitude of the response suggests that changes in snow cover and soil moisture are the primary driver of the convergent response over the terrain in both experiments. QFC also increases in both PGW and DSURF, but with larger increases in PGW due to the higher specific humidity associated with the PGW forcing.
To better understand the three-dimensional structure of the changes in near-surface winds and their role in facilitating convection through moisture transport, meridionally averaged vertical cross sections at 1200 MST for the red box in Fig. 1 are analyzed in Fig. 12. The Front Range is chosen for these cross sections due to its simple shape and proximity to a strong region of convergence as seen in Fig. 10. CTR shows prevailing westerlies for much of the vertical extent with enhanced westerlies in a localized downward plunging flow along the eastern slope and a shallow weak easterly flow in the foothills east of the Front Range (Fig. 12a). This easterly flow is a manifestation of the upslope branch of the mountain-plain solenoidal circulation common during the daytime.

There is a strengthening of this solenoidal circulation in PGW, with anomalous low-level upslope easterly winds and westerly return flow above the boundary layer (Fig. 12b). The PGW boundary layer over the mountain crest is $240 \mathrm{~m}$ deeper, likely owing to the larger warming and sensible heat fluxes over the high terrain due to the SAF. As discussed in Sect. 2, these extensions in boundary layer height may contribute to the near-surface reductions in humidity in Fig. 3. Over the mountains, where soil moisture was not as dramatically reduced, extensions in the depth of the daytime planetary boundary layer can allow drier air aloft to mix down and can mix water vapor across a larger volume. Westerly winds throughout the vertical extent of the cross section show increases upwards of $0.8 \mathrm{~m} \mathrm{~s}^{-1}$ at $5000-7000$ m. DSURF (Fig. 12c) shows even deeper anomalous easterly
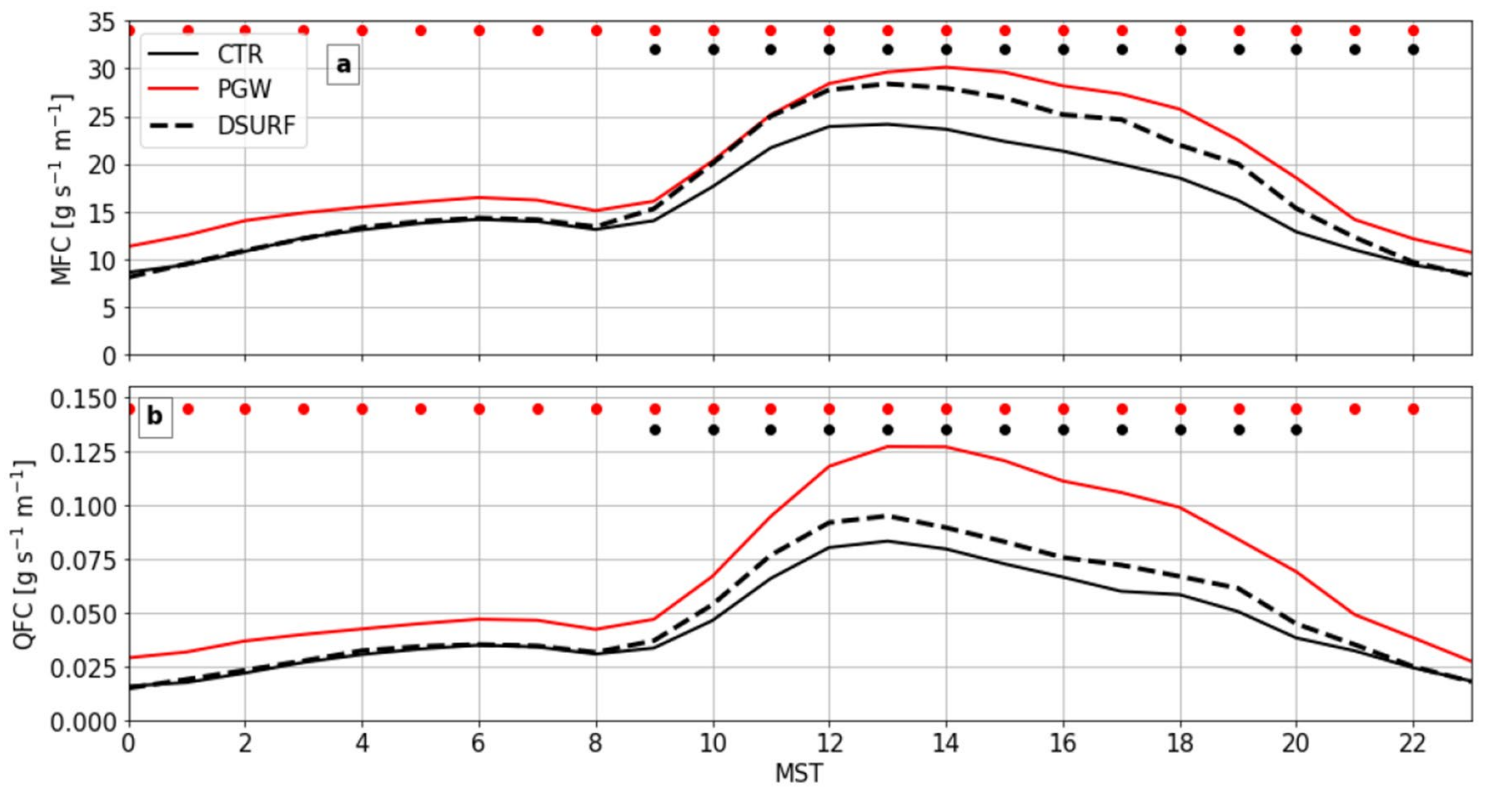

Fig. 11 Synoptically filtered April and May mean diurnal time series averaged across the mountain domain in Fig. 1 of mass flux (a) and moisture flux convergence (b). Red (PGW-CTR) and black (DSURF-
CTR) dots are representative of hours where mean differences deviate from zero at $95 \%$ confidence 

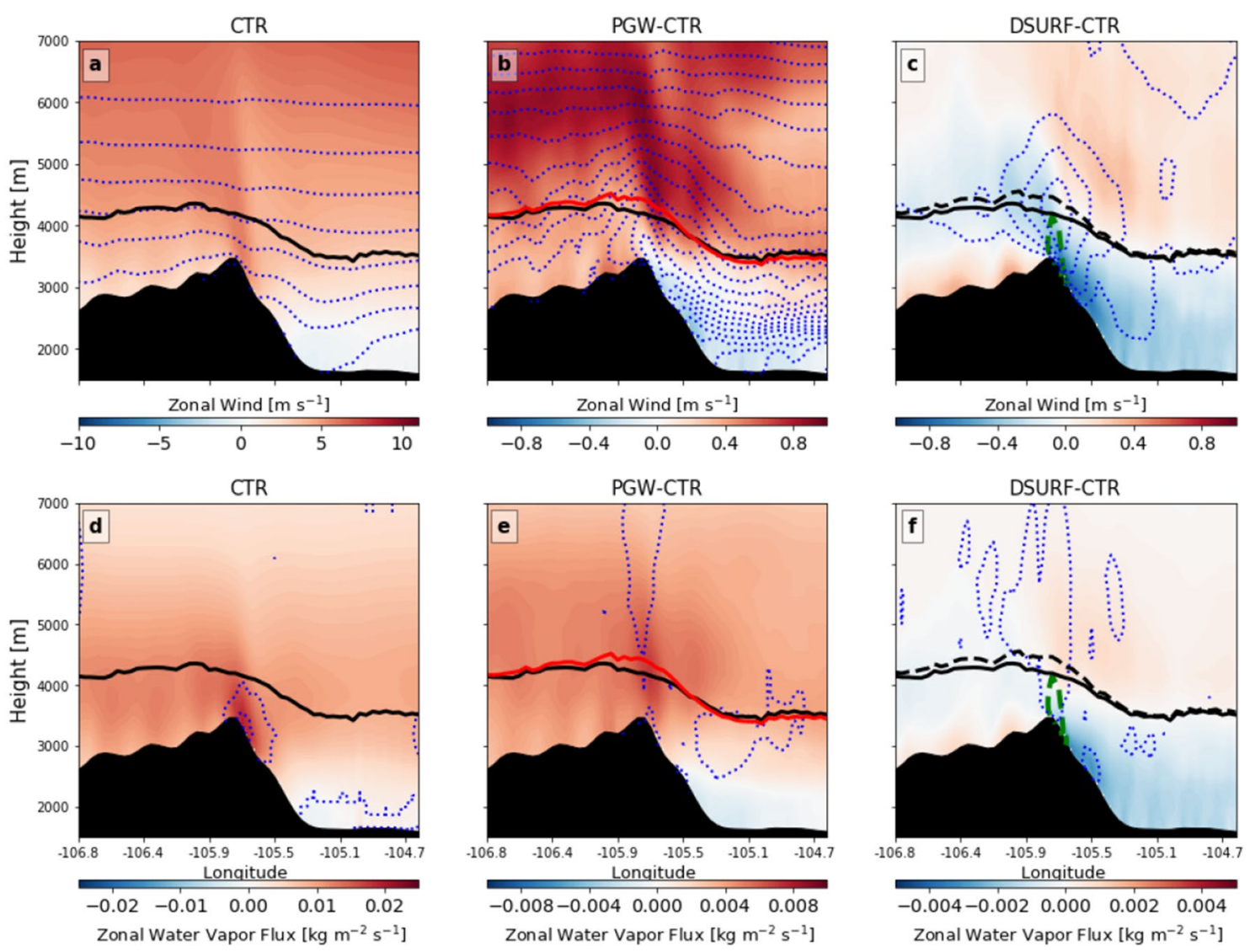

Fig. 12 Vertical cross sections meridionally averaged within the dashed red box in Fig. 1 at 1200 MST of synoptically filtered April and May mean zonal wind (shaded) and specific humidity mixing ratio contoured every $0.5 \mathrm{~g} \mathrm{~kg}^{-1}$ (blue dotted line) $(\mathbf{a}-\mathbf{c})$. Zonal water vapor flux (shaded) and cloud water mixing ratio contoured every 0.5

flow extending through much of the boundary layer giving way to anomalous westerly flow aloft. The stronger easterly response in the DSURF simulation may be attributed to the absence of increased westerly synoptic flow otherwise present in the PGW simulation which can partially counteract the strengthened thermal circulation. Increases in vertical updraft strength upwards of $0.01 \mathrm{~m} \mathrm{~s}^{-1}$ are observed at the convergence zone. The DSURF boundary layer height also compares rather well with PGW, with increases found over the mountain crest.

Compact PGW-CTR zonal specific humidity gradients that slope upwards alongside the eastern slope of the terrain indicate the importance of these enhanced thermal circulations in transporting higher moisture amounts up the slope (Fig. 12b). Additionally, DSURF shows that increased updraft strength coincides with a deep vertical protrusion of higher specific humidity concentrations above the boundary layer. Figure $12 \mathrm{~d}-\mathrm{f}$ shows zonal water vapor flux and its changes. Zonal water vapor flux maximizes at mid-levels and near the crest of the terrain, where both winds and humidity $\mathrm{g} \mathrm{kg}^{-1}$ (blue dotted line) (d-f). PGW planetary boundary layer height (red solid line), control planetary boundary layer height (black solid line), DSURF planetary boundary layer height (dashed black line), and differences in vertical motion greater than $0.01 \mathrm{~ms}^{-1}$ (green dashed line) are also shown across all plots

are relatively high. The PGW-CTR difference in Fig. 12e shows enhanced shallow easterly water vapor flux oriented up the eastern slope of the Front Range and enhanced westerly fluxes along the western slope. This response is related to the stronger convergent winds within the mountains and higher specific humidity concentrations. The DSURF-CTR easterly upslope flux in Fig. $12 \mathrm{f}$ reaffirms the importance of snow and soil moisture changes in driving this response by producing a similar pattern of anomalous easterly upslope water vapor flux. Similar to Fig. 12a-c, the deeper upslope water vapor flux in the DSURF response may be due to the lack of stronger synoptic westerlies in the PGW experiment that serve to mix down into the boundary layer and limit the vertical extent of thermally driven upslope flow. Despite this, there is good agreement between the PGW and DSURF simulations on the location and vertical distribution of these specific humidity changes and on a clear accumulation of water vapor along the crest of the Front Range.

Cloud water contours in Fig. 12d-f show how the change in winds and humidity impact clouds. CTR cloud water 
concentrations show low clouds clustered around the mountain peak at altitudes of less than $1000 \mathrm{~m}$ AGL (Fig. 12d). In PGW, increases in cloud water mixing ratio are observed in two primary locations: above the mountain peak and within the boundary layer extending from the leeside convergence zone to the adjacent plains (Fig. 12e). DSURF also shows positive anomalies in cloud water over the mountain peak that colocate with areas of positive anomalous vertical motion. This ability of the orographic thermal circulation to accumulate moisture near the mountain peak and loft it above the surface allows for the higher PWAT $_{P B L}$ concentrations and lower LCLs in Fig. $8 \mathrm{i}, 1$ that may in turn contribute to enhanced convective precipitation.

\section{Discussion and conclusions}

We have presented results from a series of RCM simulations characterizing the convective precipitation response to climate warming and the resulting perturbations in springtime snow cover and soil moisture for the Rocky Mountains. A control (CTR) and two experimental convection-permitting RCM simulations are conducted. The experimental simulations are used to represent a warmer and moister climate (PGW) and an isolated response to surface snow and soil changes (DSURF). Results show average reductions in daytime total precipitation of $4.2 \%$ for PGW and increases of $12.5 \%$ for DSURF over the high terrain. For synoptically weak days, the daytime precipitation increases by $29.7 \%$ in PGW and 28.7\% in DSURF. Agreement between the PGW and DSURF simulations on the location and magnitude of this increase in daytime precipitation suggest that reductions in snow cover are largely responsible.

The DSURF convective response over the mountains (Fig. 6a, b) is attributed to increases in both frequency and intensity of precipitation that also contribute to the PGW response (Fig. 7a, c). In PGW, during the daytime, much larger increases in intensity (Fig. 7a) are facilitated by a large-scale moistening of the atmosphere (Fig. 3c, d) along with increased low-level moisture flux convergence that maximize in the mountains where diurnal thermal orographic circulations sensitive to land surface changes converge (Figs. 10e, 11b). Precipitation frequency in PGW (Fig. 7a, b) is reduced due to increased large-scale stratification in the mid-troposphere. However, during the daytime, land surface changes act opposite this reduction and moderate the reductions in precipitation frequency. At night and in the early morning, the absence of solar heating eliminates the influence of snow loss on the convective environment, and reductions in frequency become larger while changes in intensity become small (Fig. 7a). Increases in daytime CLWP are found in both experimental simulations showing that precipitation enhancements are coincident with changes in simulated cloud properties (Fig. 6c). A small increase in cloudy updraft strength during the late morning and early afternoon may contribute somewhat to the enhanced precipitation in DSURF, though minimal changes in updraft strength are found in the afternoon (Fig. 6d). Additionally, PGW results show reductions in updraft strength during the daytime, suggesting that invigorated convective motions are not the primary cause of the precipitation increases.

The convective changes in DSURF are driven by the influence of snow cover and soil moisture changes on landatmosphere interactions. In the warmed climate, simulated fractional snow cover is reduced across the high terrain (Fig. 2c). Snow melt that occurs earlier in the season due to warmer temperatures helps to drive this response and also serves to produce positive soil moisture anomalies due to earlier replenishment (Fig. 2f). Over snow free portions of the domain, soil moisture is largely reduced through enhanced evaporation. High-elevation regions where snow loss is greatest experience large increases in absorbed shortwave radiation and strong surface warming through the snow-albedo feedback (Fig. 4a). Over low-elevation regions, the DSURF simulation shows a warming signal weaker than that over the high terrain driven by drier soils (Fig. 2f) and higher sensible heat fluxes (Fig. 4h).

The DSURF simulation, lacking the large-scale thermodynamic forcing, isolates the contribution of these land surface changes to the convective response. Over the plains, drier soils produce a warmer yet drier near-surface environment (Fig. 3b, d). Over the mountains, MCAPE and PWAT ${ }_{P B L}$ (Fig. 8c, i) increase while LCLs are lowered (Fig. 81). Strong surface warming via the SAF contributes to increased MCAPE. Soil moisture increases associated with snow melt can not sufficiently explain higher PWAT PBL $_{P}$ and lower LCLs. Instead, stronger thermally driven daytime upslope circulations increase moisture convergence over, and in the lee of, the mountains (Fig. 10e, f). This helps to increase MCAPE over the mountains while also increasing the availability of moisture for cloud condensation and convective precipitation. Additionally, stronger convergence over high terrain corresponds with strengthened mesoscale ascent that can aid in the initiation and development of convection (Fig. 12f). Tucker and Crook (2005) note similar mechanisms through which convective initiation can be enhanced. They outline that increases in the amount of convective orographic precipitation can be realized through modification to precipitation frequency via lapse rate changes or modification of precipitation intensity through an increase of available moisture. In DSURF, both of these mechanisms act in conjunction to produce the simulated increase in convective precipitation.

The PGW simulation allows for an analysis of the contribution of the mechanisms observed in DSURF to the overall climate response influenced by the imposed large scale 
warming and moistening. The vertical profile of PGW-CTR warming acts to increase stability and reduce the overall precipitation frequency. Across most of the domain, the warmer and moister atmosphere results in greater MCIN, MCAPE, and PWAT $_{P B L}$ (Fig. 8b, e, h) which contribute to increased precipitation intensity (Fig. 7c, d). Over the mountains strengthened thermally driven orographic circulations (Fig. 11a, b), caused by SAF-enhanced warming, act to compound on these changes to the thermodynamic environment through localized moisture convergence that enhances destabilization and precipitable water, allowing for increases in convective precipitation intensity. Both PGW and DSURF produce similar magnitudes of enhanced mass flux convergence, but the moister PGW atmosphere leads to larger increases in moisture flux convergence (Fig. 11b). Larger background humidity and moisture accumulations in the mountains help to produce the increase in precipitation intensity that makes up the PGW convective response. In DSURF, these increases in intensity are also accompanied by increases in frequency. In PGW, the precipitation frequency is reduced by the large scale warming pattern, but the land surface response helps to mitigate this reduction during the daytime (Fig. 7a). Warming that maximizes in the mid troposphere acts to increase stability and reduce the overall frequency of precipitation. However, over the plains, where land surface effects are weaker than the mountains, reductions in precipitation frequency for PGW are much greater (Fig. 7b) due to the absence of the significant moistening and warming of the mountains through the SAF. Alternatively, reductions in precipitation frequency may also be partially explained by energy budget constraints as a result of increased precipitation intensities, whereby the time for evaporation to replenish atmospheric moisture content takes longer (e.g., Dai et al. 2017).

Similar increases in warm-season orographic precipitation were found in Giorgi et al. (2016) who utilize a set of convection-permitting and convection parameterizing RCM simulations to evaluate the convective precipitation response over the European Alps. They find an increase in precipitation over the Alps during the months of June through August in an RCM ensemble that contrasts with the large-scale drying signal shown in global climate models. Similarly to the PGW experiment, these increases are attributed to reductions in stability connected to large localized atmospheric moisture concentrations over the mountains. Although their study did not look further at this moisture accumulation, importance was placed on alterations in thermal circulations in response to land surface changes.

In North America, Dai et al. (2017) also examine results from the simulations performed in Liu et al. (2017). Consistent with what was simulated in PGW, they note a reduction in the March, April, and May averaged light to moderate precipitation frequency over the Rocky Mountains. This reduction in PGW precipitation frequency also agrees well with prior work from Rasmussen et al. (2017) who note a reduction in the occurrence of May-June precipitation events over the high terrain in central Colorado ranging from 0 to $20 \mathrm{dBZ}$. Additionally, they find an increase in the occurrence of high reflectivity events (20-50 dBZ) comparable to the increase in the intensity of precipitation events noted in PGW. We note that enhanced warming above the surface in PGW acts to stabilize the near surface environment and inhibit precipitation frequency. These conclusions agree with recent work from Chen et al. (2020) who find an increase in the occurrence of high CAPE and high CIN values.

Results that show the intensification of diurnal orographic circulations in response to alterations in high elevation snow agree well with earlier results from Letcher and Minder (2017) who examine the thermal circulation response to changes in albedo. Later results from Letcher and Minder (2018) who note the intensification of the mountain-plain solenoidal circulation to reductions in surface albedo also show good agreement with results from the DSURF simulation that find a similar response to reductions in snow.

This study has focused on the response over high terrain on days with minimal synoptic forcing. However, a brief consideration of precipitation differences across all days indicates there may be also be changes in synoptically disturbed events. We show that the land surface, primarily snow cover, substantially contributes to the PGW daytime convective precipitation response. This is achieved through a modification of local thermal circulations that can be spatially captured using grid spacings as large as $12 \mathrm{~km}$ (e.g., Letcher and Minder 2018). However, while the larger scale thermal circulations can be captured at such resolutions, explicit representation of orographic convection necessitates the use of convection-permitting grid spacings. Future studies attempting to examine orographic convection should note this dependency of orographic precipitation on snow cover. Our results show that errors in the initialization and paramaterization of snow cover may affect convective precipitation over regions of complex terrain. Additional analysis is also needed to determine the sensitivity of these results to other model configurations. Alterations in how land surface cover, surface fluxes, and the boundary layer are paramaterized may influence the strength of the land-atmosphere interaction. Further work could also consider the influence of land-atmosphere interactions downstream of the mountains and into the summer months. Early snow melt, while allowing soil moisture to replenish sooner in the springtime, can translate to reduced soil moisture values later in the season and have an indirect impact on warm season orographic convection through influence on local convective initiation or advection of elevated mixed layers. Furthermore, soil moisture perturbations may have much stronger effects 
later into the warm season during the months of July and August, which were not considered here. Studies on topics such as these can allow for a better understanding of how land-atmosphere interactions may shape climate change over complex terrain.

Acknowledgements Support for this work was provided by NSF Grant AGS-1349990. We thank Kyoko Ikeda for providing assistance for the model configuration. High-performance computing support was provided by NCAR's Computational and Information Systems Laboratory. We would also like to acknowledge Craig Ferguson and Aiguo Dai for comments that help to improve the work.

\section{Appendix A Model verification}

Additional verification of the CTR simulation is carried out here. We compare the CTR total precipitation and mean 2-m temperature fields against the original CONUS dataset (Liu et al. 2017), the Parameter-Elevation Regressions on Independent Slopes Model (PRISM; Daly et al. 1994, 2008), and the Gridded Meteorological Ensemble Tool (GMET;
Newman et al. 2015; Monaghan et al. 2015). Additional verification of total precipitation is done with the inclusion of Stage IV (Lin and Michell 2005; Lin 2011), PERSIANN (Ashouri et al. 2015), and Daymet (Thornton et al. 2016) gridded precipitation datasets. The CTR simulation, along with all listed observational datasets, are compared against PRISM and GMET to gauge the spread of uncertainty in total seasonal precipitation. For 2-m temperature, the CTR simulation is compared to the seasonal standard deviation derived from daily values across all ensemble members for GMET.

Comparison of the total accumulated precipitation for April and May across the 12 years period is shown in Fig. 13. Broadly speaking, CONUS, PRISM, and GMET agree well on the location of the largest precipitation accumulations over the topography (Fig. 13a-c). Figure $13 \mathrm{~d}-\mathrm{f}$ shows the difference between the CTR precipitation field (Fig. 5) against the CONUS dataset used to initialize the model and force lateral boundaries and two observational datasets. Compared to CONUS, the CTR simulation produces less precipitation over the mountains (Fig. 13d). The
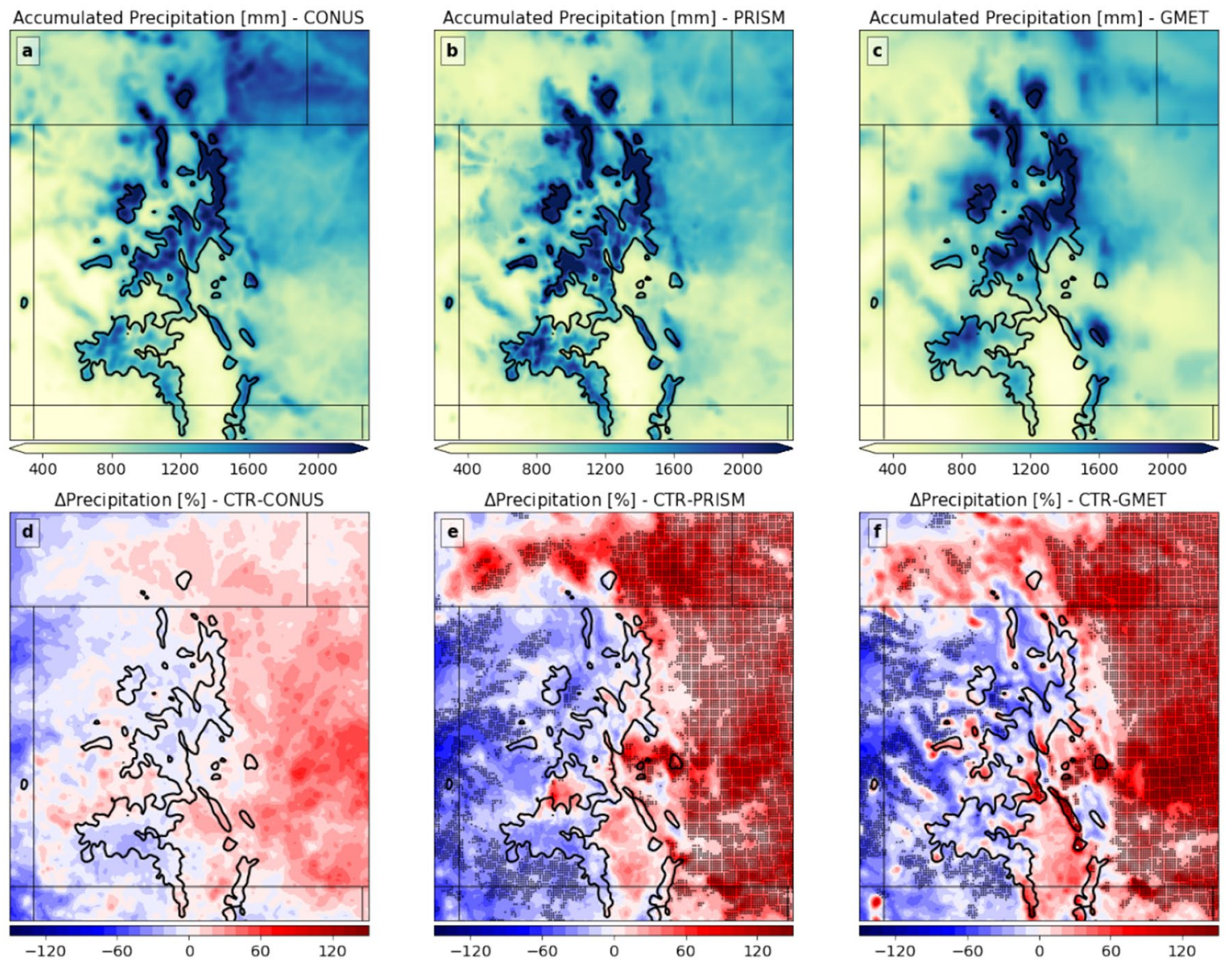

Fig. 13 Total 12-years April-May precipitation accumulation (mm) for a CONUS, b PRISM, and $\mathbf{c}$ GMET. Difference against CTR total accumulated precipitation (\%) (Fig. 5a) for d CONUS, e PRISM, and f GMET. Stipling in e, $\mathbf{f}$ is used to indicate cells where the CTR difference exceeds the difference from all other observational datasets (CONUS, PRISM, GMET, DAYMET, PERSIANN, STAGE IV) 

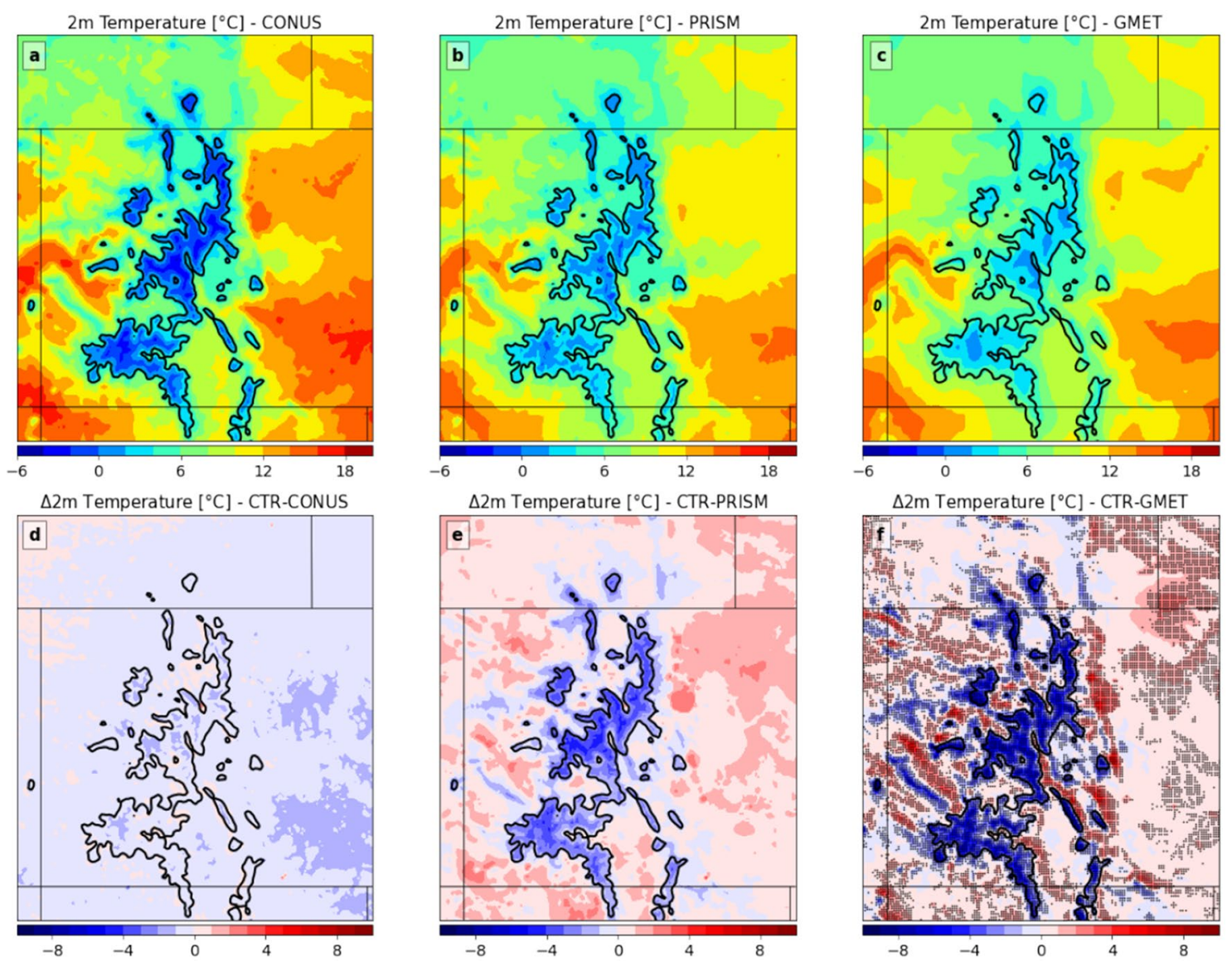

Fig. 14 Same as Fig. 13 but for the mean 12-years April-May 2-m temperature $\left({ }^{\circ} \mathrm{C}\right)$. Stipling in $f$ is used to indicate cells where the CTR difference exceeds the mean standard deviation of the GMET ensemble members

CTR-CONUS difference does not exceed $30 \%$ and is $-4 \%$ when averaged over the mountains (Fig. 13d). Further east over the plains, the CTR produces up to $60 \%$ more total precipitation than CONUS. Comparing to PRISM, the CTR simulation under-predicts precipitation by a larger margin that exceeds $30 \%$ over some higher elevation regions and extends towards the western portions of the model domain (Fig. 13e). To the east, the CTR simulation over-predicts precipitation, with biases exceeding $60 \%$ across a large swath of the domain. This bias in precipitation over the plains is largely consistent with prior verification of the CONUS model which found higher springtime precipitation east of the Rocky Mountains (Liu et al. 2017; Dai et al. 2017; Scaff et al. 2019). Lastly, compared to GMET, the CTR simulation also shows an underprediction of precipitation over the mountains extending west, and an overprediction to the east over the plains (Fig. 13f). When evaluating simulated precipitation over orography, there can be a substantial amount of uncertainty among gridded observational precipitation datasets (Lundquist et al. 2019). We place these differences within the context of the overall observational spread (GMET, PRISM, Daymet, Stage IV, PERSIANN, CONUS) in differences against PRISM and GMET in Fig. 13e,f. The results show that over the mountains, these discrepancies in total accumulated precipitation do not exceed the range of differences in observations. Towards the lower elevations, the PRISM-CTR and GMET-CTR difference is larger than the other observational datasets considered. Liu et al. (2017) show that the CONUS model does fall within the range of observational uncertainty for March-May across a larger region than what CTR shows. However, both models still show a wet bias for southeastern Wyoming and across the northern Colorado plains that exceeds the observational uncertainty.

Similarly, we compare the mean 2-m temperature field against CONUS, PRISM, and GMET in Fig. 14. CONUS, PRISM, and GMET show broad agreement on the spatial pattern of temperature across the topography and low-lying regions (Fig. 14a-c). Differencing the CTR mean 2-m temperature (Fig. 2g) against CONUS shows slightly lower temperatures in the CTR simulation that are on average $0.65{ }^{\circ} \mathrm{C}$ less for the entire domain (Fig. 14d). Compared to PRISM, the CTR simulation shows a consistent cold bias over the mountains that contrasts with a slight warm bias 
everywhere else (Fig. 14e). The average cool bias over the topography is $2.5^{\circ} \mathrm{C}$. This cool bias is larger when comparing the CTR 2-m temperature to GMET. Here, temperatures over the mountains are on average cooler by $4.1{ }^{\circ} \mathrm{C}$, and fall outside the range of uncertainty (represented by the stipling in Fig. 14f) in the GMET ensemble for most of the region. The results are consistent with prior verification done by Liu et al. (2017), who found that the CONUS March-May mean $2-\mathrm{m}$ temperature was outside the range of observational uncertainty for large portions of the same region. This CONUS cool bias is strongest during the cold months, suggesting the cause may lie in how snowcover is handled by the land-surface model. This would explain why, despite good agreement with CONUS on the mean 2-m temperature, the CTR near-surface temperature falls outside the range of observational uncertainty.

Overall, the CTR demonstrates good performance relative to CONUS. Many of the biases in CONUS against gridded observations, shown by Liu et al. (2017), such as the cool bias over the mountains and the wet bias over the eastern plains are still present in the CTR. Both the temperature bias for the mountains and precipitation bias for the plains fall outside the range of observations. However, estimates for precipitation over the mountains are not greater than the range of estimates given by observational datasets. This provides confidence in our estimate that the overall model depiction of precipitation over the region of interest is realistic.

Open Access This article is licensed under a Creative Commons Attribution 4.0 International License, which permits use, sharing, adaptation, distribution and reproduction in any medium or format, as long as you give appropriate credit to the original author(s) and the source, provide a link to the Creative Commons licence, and indicate if changes were made. The images or other third party material in this article are included in the article's Creative Commons licence, unless indicated otherwise in a credit line to the material. If material is not included in the article's Creative Commons licence and your intended use is not permitted by statutory regulation or exceeds the permitted use, you will need to obtain permission directly from the copyright holder. To view a copy of this licence, visit http://creativecommons.org/licenses/by/4.0/.

\section{References}

Ashouri H, Hsu KL, Sorooshian S, Braithwaite DK, Knapp KR, Cecil LD, Nelson BR, Prat OP (2015) PERSIANN-CDR: daily precipitation climate data record from multisatellite observations for hydrological and climate studies. Bull Am Meteorol Soc 96(1):69-83, https://doi.org/10.1175/BAMS-D-13-00068.1, https ://journals.ametsoc.org/bams/article-pdf/96/1/69/3742822/bamsd-13-00068_1.pdf

Ban N, Schmidli J, Schär C (2014) Evaluation of the convectionresolving regional climate modeling approach in decade-long simulations. J Geophys Res 119(13):7889-7907. https://doi. org/10.1002/2014JD021478

Ban N, Schmidli J, Schär C (2015) Heavy precipitation in a changing climate: Does short-term summer precipitation increase faster? Geophys Res Lett 42(4):1165-1172. https://doi. org/10.1002/2014GL062588

Banta RM (1984) Daytime boundary-layer evolution over mountainous terrain. Part 1: observations of the dry circulations. Mon Weather Rev 112(2):340-356. https://doi.org/10.1175/15200493(1984)112<0340:DBLEOM>2.0.CO;2

Barthlott C, Kalthoff N (2011) A numerical sensitivity study on the impact of soil moisture on convection-related parameters and convective precipitation over complex terrain. J Atmos Sci 68(12):2971-2987. https://doi.org/10.1175/JAS-D-11-027.1

Barthlott C, Corsmeier U, Meißner C, Braun F, Kottmeier C (2006) The influence of mesoscale circulation systems on triggering convective cells over complex terrain. Atmos Res 81(2):150-175. https ://doi.org/10.1016/j.atmosres.2005.11.010

Baur F, Keil C, Craig GC (2018) Soil moisture-precipitation coupling over Central Europe: interactions between surface anomalies at different scales and the dynamical implication. Quart J R Meteorol Soc 144(717):2863-2875. https://doi.org/10.1002/qj.3415

Carbone RE, Tuttle JD (2008) Rainfall occurence in the U.S. warm season: the diurnal cycle. J Clim 21(16):4132-4146. https://doi. org/10.1175/2008JCLI2275.1

Chen J, Dai A, Zhang Y, Rasmussen KL (2020) Changes in convective available potential energy and convective inhibition under global warming. J Clim 33(6):2025-2050. https://doi.org/10.1175/ JCLI-D-19-0461.1

Clark MP, Barlage MP, Xue L, Arnold JR, Rasmussen RM (2015) Gridded ensemble precipitation and temperature estimates over the contiguous united states. https://doi.org/10.5065/ D6TH8JR2, https://www.earthsystemgrid.org/dataset/id/d844b 548-0219-11e9-baf9-00c0f03d5b7c.html

Cohen J, Rind D (1991) The effect of snow cover on the climate. J Clim 4(7):689-706, https://doi.org/10.1175/15200442(1991)004<0689:TEOSCO>2.0.CO;2

Collins M, Knutti R, Arblaster J, Dufresne JL, Fichefet T, Friedlingstein P, Gao X, Gutowski W, Johns T, Krinner G, Shongwe M, Tebaldi C, Weaver A, Wehner M (2013) Long-term climate change: projections, commitments and irreversibility, Cambridge University Press, Cambridge, United Kingdom and New York, NY, USA, book section 12, pp 1029-1136. https://doi.org/10.1017/CBO97 81107415324.024, www.climatechange2013.org

Dai A, Rasmussen RM, Liu C, Ikeda K, Prein AF (2017) A new mechanism for warm-season precipitation response to global warming based on convection-permitting simulations. Clim Dyn. https:// doi.org/10.1007/s00382-017-3787-6

Daly C, Neilson RP, Phillips DL (1994) A statistical-topographic model for mapping climatological precipitation over mountainous terrain. J Appl Meteoroly 33(2):140-158. https://doi. org/10.1175/1520-0450(1994)033<0140:ASTMFM>2.0.CO;2

Daly C, Halbleib M, Smith JI, Gibson WP, Doggett MK, Taylor GH, Curtis J, Pasteris PP (2008) Physiographically sensitive mapping of climatological temperature and precipitation across the conterminous United States. Int J Climatol 28(15):2031-2064. https:// doi.org/10.1002/joc.1688

Davis RE, Walker DR (1992) An upper-air synoptic climatology of the western United States. J Clim 5(12):1449-1467. https://doi. org/10.1175/1520-0442(1992)005<1449:AUASCO > 2.0.CO;2

Demko JC, Geerts B (2010) A numerical study of the evolving convective boundary layer and orographic circulation around the Santa Catalina mountains in Arizona. Part II: interaction with deep convection. Mon Weather Rev 138(9):3603-3622. https:// doi.org/10.1175/2010MWR3318.1

Di Luca A, de Elía R, Laprise R (2012) Potential for added value in precipitation simulated by high-resolution nested Regional Climate Models and observations. Clim Dyn 38(5-6):1229-1247. https://doi.org/10.1007/s00382-011-1068-3 
Efron B, Gong G (1983) A leisurely look at the bootstrap, the jackknife, and cross-validation. Am Stat 37(1):36, https://doi. org/10.2307/2685844, https://www.jstor.org/stable/2685844?origi $\mathrm{n}=$ crossref

Eltahir EAB (1998) A soil moisture-rainfall feedback mechanism: 1. Theory and observations. Water Resour Res 34(4):765-776. https ://doi.org/10.1029/97WR03499

Ferguson CR, Wood EF (2011) Observed land-atmosphere coupling from satellite remote sensing and reanalysis. J Hydrometeorol 12(6):1221-1254. https://doi.org/10.1175/2011JHM1380.1

Findell KL, Eltahir EA (1997) An analysis of the soil moisture-rainfall feedback, based on direct observations from Illinois. Water Resour Res 33(4):725-735. https://doi.org/10.1029/96WR03756

Froidevaux P, Schlemmer L, Schmidli J, Langhans W, Schar C (2014) Influence of the background wind on the local soil moistureprecipitation feedback. J Atmos Sci 71(2):782-799. https://doi. org/10.1175/JAS-D-13-0180.1

Gao Y, Vano JA, Zhu C, Lettenmaier DP (2011) Evaluating climate change over the Colorado River basin using regional climate models. J Geophys Res Atmos 116(13):1-20. https://doi. org/10.1029/2010JD015278

Giorgi F, Torma C, Coppola E, Ban N, Schär C, Somot S (2016) Enhanced summer convective rainfall at Alpine high elevations in response to climate warming. Nat Geosci 9(8):584-589. https ://doi.org/10.1038/ngeo2761

Grayson RB, Western AW, Chiew FH, Blöschl G (1997) Preferred states in spatial soil moisture patterns: local and nonlocal controls. Water Resour Res 33(12):2897-2908. https://doi. org/10.1029/97WR02174

Hauck C, Barthlott C, Krauss L, Kalthoff N (2011) Soil moisture variability and its influence on convective precipitation over complex terrain. Quart J R Meteorol Soc 137(SUPPL. 1):42-56. https:// doi.org/10.1002/qj.766

Hohenegger C, Brockhaus P, Bretherton CS, Schär C (2009) The soil moisture-precipitation feedback in simulations with explicit and parameterized convection. J Clim 22(19):5003-5020. https://doi. org/10.1175/2009JCLI2604.1

Hong SY, Noh Y, Dudhia J (2006) A new vertical diffusion package with an explicit treatment of entrainment processes. Mon Weather Rev 134(9):2318-2341. https://doi.org/10.1175/MWR3199.1

Iacono MJ, Delamere JS, Mlawer EJ, Shephard MW, Clough SA, Collins WD (2008) Radiative forcing by long-lived greenhouse gases: calculations with the AER radiative transfer models. J Geophys Res Atmos 113(13):2-9. https://doi.org/10.1029/2008JD009944

Imamovic A, Schlemmer L, Schär C (2017) Collective impacts of orography and soil moisture on the soil moisture-precipitation feedback. Geophys Res Lett 44(22):11,682-11,691. https://doi. org/10.1002/2017GL075657

Jing X, Geerts B, Wang Y, Liu C (2018) Ambient factors controlling the wintertime precipitation distribution across mountain ranges in the interior western United States. Part I: Insights from regional climate simulations. J Appl Meteorol Climatol 57(8):1931-1954. https://doi.org/10.1175/JAMC-D-17-0291.1

Kalthoff N, Kohler M, Barthlott C, Adler B, Mobbs SD, Corsmeier U, Träumner K, Foken T, Eigenmann R, Krauss L, Khodayar S, Di Girolamo P (2011) The dependence of convection-related parameters on surface and boundary-layer conditions over complex terrain. Quart J R Meteorol Soc 137(SUPPL. 1):70-80. https://doi. org/10.1002/qj.686

Kendon EJ, Ban N, Roberts NM, Fowler HJ, Roberts MJ, Chan SC, Evans JP, Fosser G, Wilkinson JM (2017) Do convection-permitting regional climate models improve projections of future precipitation change? Bull Am Meteorol Soc 98(1):79-93. https ://doi.org/10.1175/BAMS-D-15-0004.1

Kimura F, Kuwagata T (1995) Horizontal heat fluxes over complex terrain computed using a simple mixed-layer model and a numerical model. 10.1175/1520-0450(1995)034<0549:HHF OCT $>2.0 . \mathrm{CO} ; 2, \quad$ papers $2: / /$ publication/uuid/ C3DE33CC-6D85-4F7D-AF61-8EEF2E5E4F7B

Kirshbaum DJ, Adler B, Kalthoff N, Barthlott C, Serafin S (2018) Moist orographic convection: Physical mechanisms and links to surface-exchange processes. Atmosphere 9(3):1-26, https://doi. org/10.3390/atmos9030080, arxiv: 0307148v2

Letcher TW, Minder JR (2015) Characterization of the simulated regional snow albedo feedback using a regional climate model over complex terrain. J Clim 28(19):7576-7595. https://doi. org/10.1175/JCLI-D-15-0166.1

Letcher TW, Minder JR (2017) The simulated response of diurnal mountain winds to regionally enhanced warming caused by the snow albedo feedback. J Atmos Sci 74(1):49-67. https://doi. org/10.1175/JAS-D-16-0158.1

Letcher TW, Minder JR (2018) The simulated impact of the snow albedo feedback on the large-scale mountain-plain circulation east of the Colorado Rocky Mountains. J Atmos Sci 75(3):755774. https://doi.org/10.1175/JAS-D-17-0166.1

Lin Y (2011) Gcip/eop surface: precipitation ncep/emc 4km gridded data (grib) stage iv data. version 1.0. https://doi.org/10.5065/ D6PG1QDD, https://data.eol.ucar.edu/dataset/21.093

Lin Y, Michell KE (2005) The NCEP stage II/IV hourly precipitation analyses: development and applications. https://doi. org/10.5065/D6PG1QDD

Liu C, Ikeda K, Rasmussen R, Barlage M, Newman AJ, Prein AF, Chen F, Chen L, Clark M, Dai A, Dudhia J, Eidhammer T, Gochis D, Gutmann E, Kurkute S, Li Y, Thompson G, Yates D (2017) Continental-scale convection-permitting modeling of the current and future climate of North America. Clim Dyn 49(1-2):71-95. https://doi.org/10.1007/s00382-016-3327-9

Lundquist J, Hughes M, Gutmann E, Kapnick S (2019) Our skill in modeling mountain rain and snow is bypassing the skill of our observational networks. Bull Am Meteorol Soc 100(12):24732490. https://doi.org/10.1175/BAMS-D-19-0001.1

Mahrt L (2006) Variation of surface air temperature in complex terrain. J Appl Meteorol Climatol 45(11):1481-1493. https://doi. org/10.1175/JAM2419.1

Mankin JS, Smerdon JE, Cook BI, Williams AP, Seager R (2017) The curious case of projected twenty-first-century drying but greening in the American West. J Clim 30(21):8689-8710. https ://doi.org/10.1175/JCLI-D-17-0213.1

Minder JR, Letcher TW, Liu C (2018) The character and causes of elevation-dependent warming in high-resolution simulations of Rocky Mountain climate change. J Clim 31(6):2093-2113. https ://doi.org/10.1175/JCLI-D-17-0321.1

Mott R, Daniels M, Lehning M (2015) Atmospheric flow development and associated changes in turbulent sensible heat flux over a patchy mountain snow cover. J Hydrometeorol 16(3):13151340. https://doi.org/10.1175/JHM-D-14-0036.1

Nelson BR, Prat OP, Seo DJ, Habib E (2016) Assessment and implications of NCEP stage IV quantitative precipitation estimates for product intercomparisons. Weather Forecast 31(2):371-394. https://doi.org/10.1175/WAF-D-14-00112.1

Newman AJ, Clark MP, Craig J, Nijssen B, Wood A, Gutmann E, Mizukami N, Brekke L, Arnold JR (2015) Gridded ensemble precipitation and temperature estimates for the contiguous United States. J Hydrometeorol 16(6):2481-2500. https://doi. org/10.1175/JHM-D-15-0026.1

Niu GY, Yang ZL, Mitchell KE, Chen F, Ek MB, Barlage M, Kumar A, Manning K, Niyogi D, Rosero E, Tewari M, Xia Y (2011) The community Noah land surface model with multiparameterization options (Noah-MP): 1. Model description and evaluation with local-scale measurements. J Geophys Res Atmos 116(12):1-19. https://doi.org/10.1029/2010JD015139 
Pielke RA (2001) Influence of the spatial distribution of vegetation and soils on the prediction of cumulus Convective rainfall. Rev Geophys 39(2):151-177. https://doi.org/10.1029/1999RG0000 72

Prein AF, Langhans W, Fosser G, Ferrone A, Ban N, Goergen K, Keller M, Tölle M, Gutjahr O, Feser F, Brisson E, Kollet S, Schmidli J, Van Lipzig NP, Leung R (2015) A review on regional convection-permitting climate modeling: demonstrations, prospects, and challenges. Rev Geophys 53(2):323-361. https://doi. org/10.1002/2014RG000475

Prein AF, Rasmussen RM, Ikeda K, Liu C, Clark MP, Holland GJ (2017) The future intensification of hourly precipitation extremes. Nat Clim Change 7(1):48-52. https://doi.org/10.1038/nclimate31 68

Rasmussen R, Liu C, Ikeda K, Gochis D, Yates D, Chen F, Tewari M, Barlage M, Dudhia J, Yu W, Miller K, Arsenault K, Grubišić V, Thompson G, Gutmann E (2011) High-resolution coupled climate runoff simulations of seasonal snowfall over Colorado: a process study of current and warmer climate. J Clim 24(12):3015-3048. https://doi.org/10.1175/2010JCLI3985.1

Rasmussen R, Ikeda K, Liu C, Gochis D, Clark M, Dai A, Gutmann E, Dudhia J, Chen F, Barlage M, Yates D, Zhang G (2014) Climate change impacts on the water balance of the Colorado headwaters: high-resolution regional climate model simulations. J Hydrometeorol 15(3):1091-1116. https://doi.org/10.1175/JHM-D-13-0118.1

Rasmussen KL, Prein AF, Rasmussen RM, Ikeda K, Liu C (2017) Changes in the convective population and thermodynamic environments in convection-permitting regional climate simulations over the United States. Clim Dyn. https://doi.org/10.1007/s0038 2-017-4000-7

Riahi K, Grübler A, Nakicenovic N (2007) Scenarios of long-term socio-economic and environmental development under climate stabilization. Technol Forecast Soc Chang 74(7):887-935. https ://doi.org/10.1016/j.techfore.2006.05.026

Riahi K, Rao S, Krey V, Cho C, Chirkov V, Fischer G, Kindermann G, Nakicenovic N, Rafaj P (2011) RCP 8.5-A scenario of comparatively high greenhouse gas emissions. Clim Change 109(1):33-57. https://doi.org/10.1007/s10584-011-0149-y

Rodriguez-Iturbe I, Entekhabi D, Bras RL (1991) Nonlinear dynamics of soil moisture at climate scales: 1 . Stochastic analysis. Water Resour Res 27(8):1899-1906. https://doi.org/10.1029/91WR0 1035

Roundy JK, Ferguson CR, Wood EF (2013) Temporal variability of land-atmosphere coupling and its implications for drought over the southeast United States. J Hydrometeorol 14(2):622-635. https ://doi.org/10.1175/JHM-D-12-090.1

Rupp DE, Li S, Mote PW, Shell KM, Massey N, Sparrow SN, Wallom DC, Allen MR (2017) Seasonal spatial patterns of projected anthropogenic warming in complex terrain: a modeling study of the western US. Clim Dyn 48(7-8):2191-2213. https://doi. org/10.1007/s00382-016-3200-x

Sato T, Kimura F (2005) Diurnal cycle of convective instability around the central mountains in Japan during the warm season. J Atmos S 62:1626-1636. https://doi.org/10.1175/JAS3423.1

Scaff L, Prein AF, Li Y, Liu C, Rasmussen R, Ikeda K (2019) Simulating the convective precipitation diurnal cycle in North America's current and future climate. Clim Dyn. https://doi.org/10.1007/ s00382-019-04754-9

Schär C, Frei C, Lüthi D, Davies HC (1996) Surrogate climatechange scenarios for regional climate models. Geophys Res Lett 23(6):669-672. https://doi.org/10.1029/96GL00265

Schär C, Lüthi D, Beyerle U, Heise E (1999) The soil-precipitation feedback: a process study with a regional climate model. J Clim 12(2-3):722-741. https://doi.org/10.1175/15200442(1999)012<0722:TSPFAP $>2.0$. CO; 2
Segal M, Garratt JR, Pielke RA, Ye Z (1991) Scaling andnumerical model evaluation of snow-cover effects on the generation and modification of daytime mesoscale circulations. https://doi. org/10.1175/1520-0469(1991)048\%3c1024:sanmeo\%3e2.0.co;2

Sheffield J, Wood EF (2008) Projected changes in drought occurrence under future global warming from multi-model, multi-scenario, IPCC AR4 simulations. Clim Dyn 31(1):79-105. https://doi. org/10.1007/s00382-007-0340-z

Skamarock C, Klemp B, Dudhia J, Gill O, Barker DE, Duda GK, Huang XY, Wang W, Powers GN (2008) A description of the advanced research WRF version 3

Song HJ, Ferguson CR, Roundy JK (2016) Land-atmosphere coupling at the southern great plains atmospheric radiation measurement (ARM) field site and its role in anomalous afternoon peak precipitation. J Hydrometeorol 17(2):541-556. https://doi.org/10.1175/ JHM-D-15-0045.1

Stewart JQ, Whiteman CD, Steenburgh WJ, Bian X (2002) A climatological study of thermally driven wind systems of the U.S. Intermountain West. Bull Am Meteorol Soc 83(5):699-708. https:// doi.org/10.1175/1520-0477(2002)083<0699:ACSOTD>2.3.CO;2

Taylor CM, Ellis RJ (2006) Satellite detection of soil moisture impacts on convection at the mesoscale. Geophys Res Lett 33(3):11-14. https://doi.org/10.1029/2005GL025252

Taylor CM, Harding RJ, Pielke RA, Vidale PL, Walko RL, Pomeroy JW (1998) Snow breezes in the boreal forest. J Geophys Res 103(D18):23087-23101. https://doi.org/10.1029/98JD02004

Thompson G, Rasmussen RM, Manning K (2004) Explicit forecasts of winter precipitation using an improved bulk microphysics scheme. Part I: description and sensitivity analysis. Mon Weather Rev 132(2):519-542, https://doi.org/10.1175/15200493(2004)132<0519:EFOWPU>2.0.CO;2, arxiv:0402.594v3

Thornton PE, Thornton MM, Mayer BW, Wei Y, Devarakonda R, Vose RS, Cook RB (2016) Daymet: daily surface weather data on a 1-km grid for North America, Version 3. https://doi.org/10.3334/ ORNLDAAC/1328, https://daac.ornl.gov/cgi-bin/dsviewer. pl?ds_id $=1328$

Truettner C, Dettinger MD, Ziaco E, Biondi F (2019) Seasonal analysis of the 2011-2017 North American monsoon near its northwest boundary. Atmosphere 10(7):420. https://doi.org/10.3390/atmos 10070420

Tucker DF, Crook NA (2005) Flow over heated terrain. Part II: Generation of convective precipitation. Mon Weather Rev 133(9):25652582. https://doi.org/10.1175/MWR2965.1

Wallace JM (1975) Diurnal variations in precipitation and thunderstorm frequency over the conterminous United States. Mon Weather Rev 103(5):406-419. https://doi.org/10.1175/15200493(1975) 103<0406:DVIPAT>2.0.CO;2

Wang G (2005) Agricultural drought in a future climate: results from 15 global climate models participating in the IPCC 4th assessment. Clim Dyn 25(7-8):739-753. https://doi.org/10.1007/s0038 2-005-0057-9

Wetzel PJ, Argentini S, Boone A (1996) Role of land surface in controlling daytime cloud amount: two case studies in the GCIPSW area. J Geophys Res 101(D3):7359-7370. https://doi. org/10.1029/95JD02134

Wi S, Dominguez F, Durcik M, Valdes J, Diaz HF, Castro CL (2012) Climate change projection of snowfall in the Colorado River Basin using dynamical downscaling. Water Resour Res. https:// doi.org/10.1029/2011WR010674

Williams CJ, McNamara JP, Chandler DG (2009) Controls on the temporal and spatial variability of soil moisture in a mountainous landscape: the signature of snow and complex terrain. Hydrol Earth Syst Sci 13(7):1325-1336, https://doi.org/10.5194/hess-131325-2009, http://www.hydrol-earth-syst-sci.net/13/1325/2009/

Zhao T, Dai A (2015) The magnitude and causes of global drought changes in the twenty-first century under a low-moderate 
emissions scenario. J Clim 28(11):4490-4512. https://doi. org/10.1175/JCLI-D-14-00363.1

Zhou X, Geerts B (2013) The influence of soil moisture on the planetary boundary layer and on cumulus convection over an isolated mountain. Part I: observations. Mon Weather Rev 141(3):10611078. https://doi.org/10.1175/MWR-D-12-00150.1
Publisher's Note Springer Nature remains neutral with regard to jurisdictional claims in published maps and institutional affiliations. 